\title{
En-Clave de género. Las mujeres fuertes del Antiguo Testamento en la Capilla de la Virgen de Guadalupe de las Descalzas Reales
}

\section{A Gender Enclave. The Strong Women of the Old Testament in the Chapel of the Virgen de Guadalupe in the Descalzas Reales}

\author{
Begoña Álvarez Seijo \\ Universidad Santiago de Compostela
}

Fecha de recepción: 14 de julio de 2017

Fecha de aceptación: 11 de enero de 2019
Anuario del Departamento de Historia y Teoría del Arte vol. 29-30, 2017-2018, pp. 143-167 ISSN: 1130-5517, eISSN: 2530-3562

http://doi.org/10.15366/anuario2017-2018.29-30.06

\section{RESUMEN}

En el presente artículo se pretende visibilizar y analizar el ciclo pictórico de la capilla de la Virgen de Guadalupe del monasterio de las Descalzas Reales, por ser una capilla creada por una mujer para mujeres. Además, el estudio se centrará en la importancia del programa dedicado a las mujeres fuertes del Antiguo Testamento, ya que es un tema poco frecuente en el Barroco español. En consecuencia, se estudiará la relevancia del monasterio como centro de poder femenino, así como la relevancia de las figuras de Sor Ana Dorotea, monja real y promotora de esta capilla mariana, ya que su personalidad y educación fueron motor indispensable para que se crease este grupo pictórico con la mujer como absoluta protagonista, y de Sebastián Herrera Barnuevo, la mano que ejecutó magistralmente la iconografía ideada por la clarisa descalza.

\section{PALABRAS CLAVE}

Descalzas Reales. Capilla de la Virgen de Guadalupe. Sor Ana Dorotea. Sebastián de Herrera Barnuevo. Mujeres fuertes de la Biblia. Iconografía femenina.

\begin{abstract}
This article intends to visualize and analyze the pictorial program of the chapel of the Virgin of Guadalupe of the monastery of the Descalzas Reales, because it is a chapel created by a woman for women. In addition, the study will focus on the importance of the program dedicated to strong women of the Old Testament, as it is a rare subject in the Spanish Baroque. Consequently, the relevance of the monastery as a center of feminine power will be studied, as well as the relevance of the figures of Sr. Ana Dorotea, royal nun and promoter of this Marian chapel, since her personality and education were indispensable to create this pictorial group with women as absolute protagonists, and Sebastián Herrera Barnuevo, the hand that masterfully executed the iconography devised by the clarisa descalza.
\end{abstract}

\section{KEY WORDS}

Descalzas Reales. Chapel of the Virgin Guadalupe. Sor Ana Dorotea. Sebastián de Herrera Barnuevo. strong biblical women. Female iconography. 
Escondida en el monasterio Nuestra Señora de la Consolación de Madrid, popularmente conocido como las Descalzas Reales, se encuentra una auténtica joya de la pintura barroca española: la capilla de la Virgen de Guadalupe, obra de Sebastián Herrera Barnuevo. Las peculiaridades de este camarín comienzan con su propia localización ya que está situado fuera del ojo público ${ }^{1}$, en el claustro alto de un convento de clausura, protegido por un bellísimo pero tupido enrejado, que dificulta la visión de las pequeñas pero maravillosas pinturas que cobija en su interior. El presente artículo tiene como principal objetivo visibilizar y poner en valor este ciclo pictórico, en concreto el programa dedicado a las mujeres fuertes del Antiguo Testamento, segunda de las peculiaridades de la pequeña capilla, ya que es un tema poco frecuente en la pintura Barroca española del siglo XVII ${ }^{2}$. En consecuencia, también se estudiarán las figuras de Sor Ana Dorotea, monja real y promotora de esta capilla mariana, ya que su personalidad y educación fueron motor indispensable para que se conserve este grupo pictórico con la mujer como absoluta protagonista, y a Sebastián Herrera Barnuevo, la mano que ejecutó magistralmente la iconografía ideada por la clarisa descalza. Asimismo, el presente trabajo se propone explicar el porqué de la excepcionalidad de este programa iconográfico desde una perspectiva de género, atendiendo a los modelos femeninos que se imponen como apropiados en la producción cultural del barroco, que son transgredidos en esta singular obra de arte.

\section{Las Descalzas Reales: un bastión de poder femenino en los siglos XVI y XVII}

El monasterio de Nuestra Señora de la Consolación fue fundado en 1559 por iniciativa de Juana de Portugal (1535-1573), hija de Carlos V, hermana de Felipe II y viuda del príncipe de Portugal quien compró el antiguo palacete en el que ella misma había nacido para levantar lo que fue uno de los centros más importantes de poder femenino de la Corona española ${ }^{3}$. Con el consejo de Francisco de Borja, su confesor, Juana decide fundar un convento de la primera orden de Santa Clara, y escogió como primeras habitantes de la nueva fundación a las monjas de Santa Clara de Gandía, ya que habían sido la primera congregación que había asumido la reforma clarisa de Santa Coletta de Beulatt, que abogaba por la estricta observancia de la primitiva regla ${ }^{4}$. Doña Juana deseaba que el convento fuese un monumento a su memoria como benefactora y promotora, donde se rogase por su alma y que evidenciase su devoción y cercanía a Dios ${ }^{5}$.

El emplazamiento escogido por doña Juana fue el palacio del tesorero real Alonso Gutiérrez, lugar en el que la propia infanta había nacido y pasado parte de su infancia junto con su hermana, la emperatriz María. Por lo que el monasterio no fue levantado sobre un solar vacío sino que se utilizó una finca ya edi-

\footnotetext{
1 Actualmente la capilla forma parte del recorrido de las visitas guiadas al monasterio que realiza Patrimonio Nacional, aunque las pinturas no se pueden apreciar en todo su esplendor, ya que permanecen ocultas tras el enrejado, el cual no se abre al público durante las visitas.

${ }^{2}$ La representación de estas mujeres fuertes de la Biblia cobra relevancia en el siglo XVIII en ciclos similares al de la capilla de la Guadalupe de las Descalzas; sin embargo, a excepción de las pinturas al fresco de la bóveda del triunfo de la pureza de María de la iglesia de El Escorial de Lucas Jordán (1693), las pinturas perdidas de las pechinas de la Capilla de Nuestra Señora del Buen Consejo (h. 1650), también obra de Herrera Barnuevo, y la propia capilla de la Virgen de Guadalupe, no hemos encontrado otras representaciones pertenecientes al siglo XVII. Amparo AlBa y Guadalupe SEIJAS, "Las mujeres fuertes de la Biblia y su pervivencia en la pintura española del siglo XVII", en G. Seijas de los Ríos-Zarzosa (ed.), Mujeres del Antiguo Testamento: de los relatos a las imágenes, Aletheia, Estella, Editorial Verbo Divino, 2015, pp. 93-124

3 María Leticia SÁnchez HernÁndez, "Católicas y Reformadas: apuntes iconográficos de dos formas de relación bíblica”, en M. L. Giordano y A. Valerio (eds.), Reformas y Contrarreformas en la Europa católica (siglos XVI-XVII), Estella, Verbo Divino, 2016, pp. 133-154.

4 Para más información sobre la fundación de monasterio, véase María Leticia SÁnchez Hernández, Patronato regio y órdenes religiosas femeninas en el Madrid de los Austrias: Descalzas Reales, Encarnación y Santa Isabel, Madrid, Fundación Universitaria española, 1997, pp. 27-36.

5 María Leticia SÁnchez Hernández, "Servidoras de Dios, leales al Papa. Las monjas de los monasterios reales”, Libros de la Corte, Monográfico 1, Año 6 (2014), pp. 293-318.
} 
ficada, como explica $\mathrm{M}^{\mathrm{a}}$ Ángeles Toajas ${ }^{6}$. Esto le otorga gran parte de la singularidad arquitectónica al complejo conventual, pues su tipología responde, más que un monasterio, a una residencia palaciega con la estructura típica de las casas aristocráticas del Madrid de la época, a pesar de que fruto del paso de los años se haya ido revistiendo la estructura primigenia. Esto fue así porque además de abaratar el coste de la construcción del complejo, el monasterio debía cumplir diversas funciones: junto con la de albergar a la congregación de franciscanas descalzas y cumplir los deseos piadosos y devocionales de la reina regente, también fue concebido como residencia y mausoleo real, pues doña Juana residió intermitentemente en el monasterio entre 1560 y 1573 y acondicionó en él un lugar para su propio enterramiento 7 .

Las reformas que la princesa portuguesa realizó en el palacio fueron escasas; casi todas ellas se centraron en la iglesia monástica, ya que iba a ser el lugar que albergase sus restos y su capilla funeraria, que la conectarían con la divinidad y desde la que se rogaría por el descanso eterno de su alma. Se trató de una obra de gran monumentalidad sobria y solemne pero que al mismo tiempo aportaba modernidad y nuevas formas a la arquitectura madrileña de aquel momento ${ }^{8}$. El templo se levantó bajo las órdenes del arquitecto Juan Bautista de Toledo, consagrándose la iglesia cinco años después de la llegada a Madrid de las clarisas de Gandía, en el año $1564^{9}$. Por su parte, el edificio conventual, singular, como decíamos, por su estructura palaciega, fue concebido por doña Juana como un espacio que hoy en día denominaríamos multifuncional, pues albergaba, además de la iglesia y las dependencias para la comunidad de religiosas, el Cuarto Real, que consistiría en una zona de residencia para familia real y la propia Juana, las dependencias para el servicio, la casa de Capellanes, el hospital de la Misericordia o Casa Real de la Misericordia, y estructuras para el mantenimiento del convento como una tahona, una vaquería y un huerto ${ }^{10}$.

La protección de la familia real, su constante presencia en el monasterio y los destacados linajes de las monjas residentes hizo que en muy pocos años las Descalzas Reales se convirtiese en uno de los más importantes centros de poder femenino de la Monarquía Hispánica. Las familias más distinguidas de la Monarquía y de los territorios ligados a la misma querían un lugar en las Descalzas para sus miembros femeninos, pues esto suponía una apertura hacia las relaciones de poder con la corona y aseguraba la defensa de sus intereses y el establecimiento de una red de contactos con el resto de familias con peso político y económico del Estado ${ }^{11}$. De este modo, una plaza en el monasterio se convirtió en una valiosa recompensa para la nobleza Europea, pues el ingreso de una mujer de la familia suponía introducirse en un entramado de opulencia estrechamente adherido a la prosapia de los Habsburgo, lo cual podía facilitar la ascensión social y el ejercicio de los dispositivos de alianzas ${ }^{12}$.

Esto supuso que las religiosas descalzas que allí residieron, pertenecientes a los principales apellidos y títulos nobiliarios de la España de la época, ya fuesen Borja, Pacheco, Portocarrero, Rojas ${ }^{13}$, o de la pro-

${ }^{6} \mathrm{M}^{\mathrm{a}}$ Ángeles Toajas Roger, "Palacios ocultos: las Descalzas Reales de Madrid”, en B. J. García García (ed.), FELIX AUSTRIA. Lazos familiares, cultura política y mecenazgo artístico entre las cortes de los Habsburgo, Fundación Carlos de Amberes, 2016, pp. 329-374.

7 Sobre la Capilla funeraria de Juana de Portugal en las Descalzas Reales: Javier ORTEGA VIDAL, "La capilla sepulcral de doña Juana de Austria en las Descalzas Reales. Una joya en la penumbra”, Reales Sitios, 138, 1998, pp. 40-54; Ana GARCíA SANZ, "Nuevo datos sobre los artífices de la capilla funeraria de Juana de Austria", Reales Sitios, 155 (2003), pp. 16-25.

8 TOAJas Roger, 2016, p. 358

9 Ana García SAnz, "El Monasterio de las Descalzas Reales: arte, espiritualidad en el Madrid de los Austrias", en A. García Sanz (ed.), Pinturas murales de la escalera principal. Monasterio de las Descalzas Reales, Madrid, 2010, pp. 11-39.

10 GARcía SANZ, 2010, p. 13.

11 Rocío Martínez López, "Sor Mariana de la Cruz y Sor Ana Dorotea de Austria: el poder de las Religiosas Habsburgo de las Descalzas Reales de Madrid”, en C. López Calderón, Mª A. Fernández Valle y I. Rodríguez Moya (coords.), Barroco Iberoamericano: identidades culturales de un imperio, Santiago de Compostela, Andavira Editora, 2013, vol. 1, pp. 165-180.

12 Magdalena S. SÁnchez, "Where Palace and Convent Met: The Descalzas Reales in Madrid", Sixteenth Century Journal 46, $\mathrm{n}^{\circ} 1$ (2015), pp. 53-82.

13 Karen Vilalcoba Ramos y María Teresa Muñoz Serrulla, "Las religiosas de las Descalzas Reales de Madrid en los siglos XVI-XX: fuentes archivísticas”. Hispania sacra, Madrid, n.125 (2010), pp. 115-156; SÁNCHEZ HernÁNDEZ, 1997, p. 79. 
pia familia real, desarrollasen su educación en un entorno propicio para el crecimiento cultural e intelectual, haciendo que muchas de ellas fuesen personalidades de gran relevancia para importantes acontecimientos históricos que se desarrollaron en la convulsa España de los siglos XVI y XVII ${ }^{14}$. De este modo, las mujeres que habitaron las Descalzas eran figuras procedentes de los más importantes linajes que se escapaban a la norma impuesta para género femenino en la época pues la reclusión les dio acceso a una educación y un poder que se entendía inherente únicamente al género masculino ${ }^{15}$. Por lo tanto, las Descalzas Reales era un monasterio particular por diversos motivos: por un lado, por su arquitectura, ya que presentaba una tipología propia de un palacio aristocrático madrileño; en segundo lugar, por su proximidad con el poder regio, pues fue pensado como residencia y lugar de enterramiento de doña Juana de Austria, y porque en él se hospedaron y residieron importantes miembros de la familia Habsburgo; así como por la alta alcurnia de las monjas que podían habitar en él.

Además de doña Juana, pertenecientes a la familia real, también estuvieron alojadas las infantas Isabel Clara Eugenia y Catalina Micaela, tras la muerte de su madre Isabel de Valois en 1568, y después, en 1580, junto a sus hermanos Diego y Felipe, tras la muerte de la última de las mujeres de Felipe II, Ana María de Austria. Pero sin duda, después de la fundadora, la personalidad más importante que habitó el Cuarto Real $^{16}$, fue su hermana, la emperatriz María ${ }^{17}$, esposa de Maximiliano II, quien había pasado con doña Juana parte de su infancia en el palacio de Alonso Gutiérrez, y que también se habitó en el monasterio, lo mismo que su hija, Margarita de Austria. Madre e hija, elevaron la reputación y el poder del monasterio hasta su cima más alta, pues ambas fueron muy influyentes en asuntos de Estado, interviniendo para que el Monarca apoyase y actuase siempre en defensa de los intereses de su familia en el Imperio, la dinastía de los Habsburgo, siendo figuras clave para el acontecer de la política del reino ${ }^{18}$. Asimismo, el monasterio fue empleado como palacio de retiro por la reina Margarita de Austria, esposa de Felipe III, y su hija, la infanta Ana Mauricia. Como explica Ana García Sanz, fueron estas buenas relaciones entre las mujeres de la familia real las que propiciaron el surgimiento de un espacio conventual diferente, ya que servía tanto para el desarrollo de la vida espiritual y el desapego de la vida mundana de las religiosas enclaustradas, como para el florecimiento de un ambiente cortesano a través de las relaciones de las mujeres reales que allí habitaron, en especial en torno a la figura de la emperatriz María ${ }^{19}$.

Tras el fallecimiento de la emperatriz en 1603, su hija, Sor Margarita de la Cruz, continuó con su labor de salvaguarda de los intereses de la Casa de Austria y de desarrollo de una corte femenina dentro de los muros del monasterio. La princesa alemana, sobrina del rey Felipe II, fue una mujer de profunda vocación religiosa, que se trasladó con su madre al convento y tomó los hábitos a la edad de diecisiete años, rechazando, de ese modo, convertirse en la quinta mujer del monarca ${ }^{20}$. Su gran personalidad tuvo gran relevancia en la sociedad del siglo XVII, admirada y respetada, por su pertenencia al círculo más cercano de la realeza, como por su profunda religiosidad, lo que la condujo a que distintos Papas a lo largo de su vida le otorgasen breves en los que se reconocía su valía y entrega como monja de clausura pero en los que tam-

\footnotetext{
14 Martínez López, 2013, p. 168.

15 Mariló Vigil, La vida de las mujeres en los siglos XVI y XVII, Madrid, Siglo XXI, 1994, pp. 208-238; Mariló VigIL, “Conformismo y rebeldía en los conventos femeninos de los siglos XVI y XVII”, en Ma M. Graña Cid y A. Muñoz Fernández (coords.), Religiosidad femenina: expectativas y realidades (siglos VIII-XVIII), Madrid, Asociación Cultural Al-Mudayna, 1991, pp. 165-186; Ana ARANDA BERnAL, "La participación de las mujeres en la promoción artística durante la Edad Moderna". Goya. Revista de Arte, Edición Fundación Lázaro Galdiano, 301-302 (2005), pp. 229-240.

16 Dependencia que se construyó para Juana de Austria y que habitó el resto de la familia real que se hospedó o residió en el convento franciscano.

${ }^{17}$ María de Austria fue Infanta de España, Archiduquesa de Austria y, debido a su matrimonio con Maximiliano II, fue Emperatriz del Sacro Imperio y reina consorte de Bohemia y Hungría. Se traslada con su hija, la archiduquesa Margarita de Austria, al monasterio madrileño de Nuestra Señora de la Consolación en 1582 y habitó en el mismo hasta su muerte en 1603.

18 Martínez López, 2013, pp. 168-169.

19 GARCía SANZ, 2010, p. 15.

20 SÁNCHEZ HERNÁNDEZ, 2014, p. 302.
} 
bién se le pedía intercesión con la Corte española a favor de la Iglesia. ${ }^{21}$ Así lo cuenta su biógrafo y padre confesor, Juan de Palma, que a modo de un diario de la vida de la religiosa, relata el amor por Cristo de la monja y su completa entrega a reunirse con Él en la vida eterna, en una suerte de biografía hagiográfica orientada a apoyar el proceso para su beatificación y canonización iniciado tras su muerte ${ }^{22}$.

Por otro lado, a Sor Margarita de la Cruz, le debemos la llegada a Madrid de otras de las religiosas más destacadas de las Descalzas, pues buscó en su sobrina ilegítima, Sor Ana Dorotea, a una digna sucesora de la empresa que se había encomendado. Sor Ana Dorotea de Austria, nació hacia 1612, hija ilegítima del emperador Rodolfo II, hijo de la emperatriz María y hermano de Sor Margarita de la Cruz, y de Catalina de Estrada $^{23}$. Ingresa muy niña en el convento de San Agustín de Viena pero, por petición de su tía, es trasladada a España para ingresar en las Descalzas, donde, tras ser educada por Sor Margarita, tomó los hábitos en 1628 con dieciséis años ${ }^{24}$. La educación que le aportó su tía llevó a Sor Ana Dorotea a ser una personalidad influyente tanto dentro como fuera de los muros del monasterio; la correspondencia que de su mano se conserva con Felipe IV ${ }^{25}$ o con los papas Alejandro VII, Clemente X e Inocencio XI, son prueba de que su poder iba más allá de los muros del claustro, siendo una parte activa en la política y las relaciones de la Monarquía Hispánica ${ }^{26}$. De este modo, la religiosa fue capaz de articular una poderosa red de contactos que le permitieron convertirse en una de las mujeres mejor consideradas de su época y también una de las mejor informadas de todo el siglo, con capacidad para intervenir en toda clase de asuntos que afectasen a la dinastía Habsburgo ${ }^{27}$.

En la clausura, Sor Ana Dorotea llevó a cabo una intensa labor de mecenazgo artístico que enriqueció el convento, función que cumplió brillantemente gracias a una exquisita educación y gusto por las artes y cultura de su época, que la condujo a establecer relaciones con grandes pintores de la época como Rubens, que la retrata para su profesión en $1628^{28}$. De este modo, promovió la realización de importantes obras en el monasterio, entre las cuales destacan, sin duda, la obra que aquí nos ocupa, la Capilla de la Virgen de Guadalupe que encargó al pintor madrileño Sebastián Herrera Barnuevo, así como la restauración de la escalera principal ${ }^{29}$, cuyo programa iconográfico es un magnífico ejemplo tanto de la personalidad de las monjas Descalzas como de la propia Sor Ana Dorotea, ya que testimonia la creencia en el binomio fe-política tan característico de estas mujeres ${ }^{30}$.

21 SÁnChez Hernández, 2014, p. 303.

22 Juan de la Palma, Vida de la serenísima infanta sor Margarita de la Cruz, religiosa descalza de Santa Clara, Madrid, 1636.

23 Algunos estudios recientes proponen hipótesis que ponen en duda la maternidad de Catalina de Estrada: Vanessa DE CRUZ MedinA, “An illegitimate Habsburg. Sor Ana Dorotea de la Concepción, Marquise of Austria”, en Anne J. Cruz y María Galli Stampino (eds.), Early modern Habsburg women : transnational contexts, cultural conflicts, dynastic continuities, Forthcoming, Ashgate, 2012.

24 Juan DE la PALma, Vida de la serenísima infanta sor Margarita de la Cruz, religiosa descalza de Santa Clara, Libro VI, Madrid, 1636, p. 157r.

25 Véase Karen María Vilacoba Ramos, "Entre Dios y la corona: Relaciones epistolares de Sor Ana Dorotea y Felipe IV”, en M. M. Graña Cid (ed.), El Franciscanismo en la península ibérica. Balance y perspectivas, Barcelona, G.B.G, 2005 , pp. 643-661.

26 SÁNCHEZ HERNÁNDEZ, 2014, p. 304.

27 De la correspondencia que se conserva entre Sor Ana Dorotea y el monarca Felipe IV, sabemos que intentó influir para que se reforzasen las relaciones entre España y el Imperio, pues no hay que olvidar que ella era hija de Rodolfo II, y por ello presiona al monarca para que se produjese la alianza matrimonial entre el primogénito de Felipe IV, Baltasar Carlos, y Mariana de Austria, hija de Fernando III. Sor Ana Dorotea consigue sus objetivos, pero la prematura muerte del príncipe en 1646 trunca los planes de alianza y pone al monarca en una situación difícil al carecer de heredero, situación que se arreglaría con el matrimonio del propio Felipe IV con Mariana de Austria, prometida de su hijo. MarTínez LóPez, 2013, pp. 172-173.

28 GARCía SANZ, 2010, p. 20.

29 Hay controversia sobre quién y cuándo se llevó a cabo la magnífica decoración de la escalera principal de las Descalzas, a lo que contribuye la presencia de una placa con la inscripción de que la promotora de la restauración fue Sor Ana Dorotea de Austria en 1684. Véase Miguel MorÁn Turina, "La escalera del convento de las Descalzas Reales de Madrid", en A. García Sanz (ed.), Pinturas murales de la escalera principal. Monasterio de las Descalzas Reales, Madrid, 2010, pp. 39-55.

30 SÁNCHEZ HERNÁNDEZ, 2014, p. 304. 


\section{Sebastián Herrera Barnuevo: un olvidado artista total ${ }^{31}$}

Sor Ana Dorotea realiza el encargo de que se lleve a cabo una capilla dedicada a la Virgen de Guadalupe en el ala Este del claustro alto, en 1653, y elige como responsable de la creación y ejecución del proyecto al pintor, escultor y arquitecto madrileño Sebastián de Herrera Barnuevo.

Nacido en Madrid en 1619, Herrera Barnuevo es una figura que ha sido nombrada en muchas ocasiones, pero no estudiada en profundidad. El primero en hacer un análisis de esta personalidad del Barroco madrileño es Harold E. Wethey, quien estudia el trabajo de Barnuevo en la actual Colegiata de San Isidro, en un artículo en $1954^{32}$. Fue un artista que cultivó con audacia las tres artes mayores (arquitectura, escultura y pintura) y que desarrolló amplios conocimientos en teoría del arte, lo que le condujo a buscar un ennoblecimiento del trabajo de artista y a especular con modelos arriesgados e intelectuales que miraban hacia Italia y Flandes ${ }^{33}$. Sin embargo, a pesar de poseer una personalidad definida y un estilo dinámico, y de haber desempeñado importantes puestos en la Corte, tanto como pintor como de arquitecto, su figura cayó en el olvido por la sombra de su famoso maestro, el granadino Alonso Cano, y por la desventura y los avatares que sufrieron los monumentos de Madrid durante la desamortización y la Guerra Civil española ${ }^{34}$.

$\mathrm{Su}$ formación comienza con el desarrollo de sus dotes como escultor en el taller de su padre ${ }^{35} \mathrm{y}$, más tarde, alrededor de 1638, fue enviado al taller de Alonso Cano, poco después de que el maestro sevillano se estableciese en Madrid en la primavera de ese mismo año ${ }^{36}$. De Cano dependerá la formación de Herrera como pintor y también como arquitecto. ${ }^{37}$ Como explica Pérez Sánchez, ya en 1645 participa con su maestro en la realización del retablo de Nuestra Señora de la Paz de la Magdalena de Getafe, con una Adoración de los pastores, donde se aprecia la gran influencia de su preceptor y el carácter de Correggio ${ }^{38}$. Antonio Palomino al referirse a Herrera, dice que "se arrimó a la escuela de Alonso Cano, más por imitación que

31 El título de este epígrafe pretende destacar la figura de Sebastián Herrera Barnuevo como un artista que destacó en todas las disciplinas artísticas que realizó, y que a pesar de los numerosos estudios que existen y ponen en valor su faceta de arquitecto y trazador, todavía son escasos los trabajos que se centren en su faceta como pintor dada la elevada calidad de su obra a pesar de no haya sobrevivido un elevado número hasta nuestros días. Sobre su papel como arquitecto véase Enrique LLAGUNO Y Amirola, Noticias de los arquitectos y arquitectura de España, desde su restauración por el Excmo. Señor D. Eugenio Llaguno y Amirola ; ilustradas y acrecentadas con notas, adiciones y documentos por Juan Agustín Cean-Bermúdez, Madrid, Imprenta Real, 1829; Virginia Tovar MARTín, Los arquitectos madrileños de la segunda mitad del siglo XVII, Madrid, CSIC, 1975; Virginia Tovar Martín, Arquitectura Madrileña del siglo XVII (datos para su estudio), Madrid, Instituto de Estudios Madrileños, 1983; María del Carmen Cayetano Martín, Pilar Flores Guerrero y Cristina Gallego Rubio: "Sebastián de Herrera Barnuevo, Maestro Mayor de las obras de Madrid (1665-1671)", Villa de Madrid, 27 (1989), pp. 49-56.

32 Harold E. Wethey, "Herrera Barnuevo's work for the Jesuits of Madrid”, The Art Quartely (1954), pp. 335-344, con traducción al castellano en "Herrera Barnuevo y su capilla de las Descalzas Reales", Reales Sitios 13 (1967).

33 Cipriano García-Hidalgo de Villena, "Sebastián de Herrera Barnuevo y su intervención en la capilla de San Isidro de Madrid”, Cuadernos de arte e iconografia, tomo XVI, no 32 (2007), pp. 357-384.

34 García-Hidalgo de Villena, 2002, pp. 358-360.

35 Proveniente de una familia de artistas, su padre era un importante escultor de principios de siglo, Antonio Herrera, que llegó a ser escultor del rey y aparejador de obras reales. Alfonso E. PÉrez SÁnchez, Pintura Barroca en España (1600-1750), Madrid, Cátedra, 1992, p. 303; Abraham DíAz GARCíA, "Nuevos datos sobre Sebastián Herrera Barnuevo en los Recoletos Agustinos y en el Colegio Imperial de Madrid", Anuario del Departamento de Historia y Teoría del Arte, vol. XVII, 2005, pp. 51-66.

36 Harold E. Wethey y Alice Sunderland Wethey, "Herrera Barnuevo and his Chapel in the Descalzas Reales", The Art Bulletin, vol. 48, no 1 (1966), pp. 15-34; Fernando COLLAR CÁCERES, "Notas sobre Sebastián Herrera Barnuevo, pintor”, Anuario del Departamento de Historia y Teoría del Arte, vol. XV, 2003, pp. 113-124.

37 Esta relación con Alonso Cano como maestro de pintura y arquitectura no está del todo clara según Abraham Díaz García, quien a pesar de lo expuesto por Antonio Palomino y posteriormente afirmado por Wethey, Pérez Sánchez o Collar Cáceres, explica que no está clara la formación de Herrera junto con el Racionero, a pesar de la deuda estilística que se aprecia en sus primeras obras pictóricas, pues no figura entre los aprendices de Cano, por lo que pudo haber sido formado por el printor granadino o con otro pintor establecido en Madrid y, tras la llegada de Cano en 1638, abrazar los modelos y el estilo de éste. Abraham DíAz GARCíA, “Sebastián de Herrera Barnuevo (1619-1671). Obra pictórica”, Cuadernos de arte e iconografía, tomo XIX, n³7 (2010), pp. 9-251.

38 PÉrez SÁNCHEZ, 1992, p. 304. 
por disciplina" ${ }^{39}$, sin embargo, tanto Wethey y Sunderland como Pérez Sánchez aprecian que la influencia de Cano es relativa, pues en sus obras de madurez se aprecia una fuerte admiración por Venecia, sobre todo por Tintoretto y Veronés ${ }^{40}$. Como aclara Collar Cáceres, en las obras de Herrera el carácter deudor de Cano está presente en el sentido plástico, en el dominio del dibujo, en la limpieza de las formas y en el tratamiento de los paños, es decir, en los rasgos más generales y conceptuales, fruto de haberse formado a su lado, pero no se aprecia una simple imitación de sus motivos concretos ${ }^{41}$. En realidad, además de tener un gran talento Herrera poseía una gran capacidad de asimilación de las tendencias foráneas; su presencia en el taller de Cano, le permitió entrar en contacto con multitud de grabados procedentes de Flandes e Italia y, debido al trabajo de su padre, Antonio Herrera, como escultor de Corte, tenía acceso libre al Alcázar madrileño en un momento en el que la Corte brillaba tanto por sus maestros coetáneos como por la gran presencia de obras extranjeras. Esta amalgama de influencias, dio como fruto una obra que, aunque con inspiración y modelos heredados de su maestro, estaba en consonancia con la producción artística de personalidades coetáneas al pintor madrileño como Carreño, Rizzi o Herrera "el Mozo"; una obra cargada de dinamismo y barroquismo en la que se apreciaba su asimilación de estilos, tipologías y modos foráneos a un estilo personal y creativo ${ }^{42}$.

En síntesis, se puede establecer que las fuentes a las que Herrera Barnuevo recurre para realizar sus obras son dispares, estando presentes en su producción artística: el genio de Cano en sus obras de juventud, como la Adoración de los pastores de Getafe, pero donde también se aprecia su gusto por Correggio o Bassano; una gran influencia los pintores del Renacimiento veneciano en sus obras de madurez, que se observa en la presencia del color y el tratamiento de las figuras de Tinroretto o Veronés en sus mujeres fuertes de la Capilla de la Virgen de Guadalupe; en otras obras, como la famosa Trinidad de la Tierra del Colegio Imperial de Madrid se distingue como la composición de Herrera dialoga con obras de Rubens; e incluso, en obras como la Inmaculada Concepción del Museo del Louvre, antes atribuida a un seguidor valenciano de Ribera, se observa una influencia de la tipología riberesca, y que por la presencia de los ángeles, nacidos de las obras de Alonso Cano, hoy se considera creación indiscutible de la mano de Herrera Barnuevo ${ }^{43}$.

Fue precisamente su formación interdisciplinar y el carácter y calidad de sus obras lo que hizo que Herrera lograse dos títulos de gran importancia en el seno de la Corte madrileña. Por un lado, debido a sus dotes como retratista fue pintor de Cámara durante dos años, sucediendo en el puesto a Juan Bautista Martínez del Mazo en 1667, pero tuvo que abandonarlo en 1669, siendo sustituido por Carreño de Miranda, debido a una resentida salud que le obligó a abandonar su trabajo como artista. Ostentando este puesto fue cuando realizó el retrato del monarca, Carlos II, de la colección Gil Nebot (Barcelona) ${ }^{44}$. Asimismo, gracias a su trabajo como arquitecto y trazador, ocupó el cargo de Maestro de Obras Reales desde $1662^{45}$ y aunque muchas de sus obras no han llegado a nuestros días, las que se conservan, junto los dibujos de trazados de otras, permiten intuir a Herrera como un claro ejemplo de lo que se denomina arquitectura plástica o pictórica, deudora de la interdisciplinaridad de su formación, abriendo camino a otros arquitectos reales como Herrera "el Mozo" o Teodoro Ardemans ${ }^{46}$.

\footnotetext{
39 Antonio Palomino y Velasco, Museo pictórico y escala óptica, III. El parnaso español pintoresco y laureado, Madrid, 1947, p. 968.

40 Wethey y Sunderland, 1966, pp. 15-17; Pérez Sánchez, 1992, p. 304.

41 Collar Cáceres, 2003, p. 115.

42 García-Hidalgo de Villena, 2002, pp. 360-361.

43 Collar CÁceres, 2003, pp. 115-117.

44 Collar Cáceres, 2003, p. 114. Álvaro Pascual Chenel, "Un nuevo retrato ecuestre de Carlos II, por Herrera Barnuevo", Archivo Español de Arte, CSIC, 310 (2005), pp. 179-184.

45 PÉreZ SÁnCheZ, 1992, p. 304.

46 García-Hidalgo de Villena, 2007, p. 363.
} 
De todo lo que se ha destacado de la vida y obra de Herrera hay dos aspectos cruciales para la comprensión de su creación en la capilla de las Descalzas Reales: por un lado, su formación como artista en las tres artes mayores, maestro en arquitectura, pintura y escultura, lo cual, junto con su fértil y audaz inventiva, lo hacía un experto en grandes proyectos que conjugaban las tres artes en una suerte bel composto berniniano; y, por otro lado, su gusto por la obra de los artistas venecianos, como Veronés y Tintoretto, sobre todo de éste último, por la influencia que van a tener sus estilos en las composiciones pictóricas de la capilla, tema central del presente artículo, y que junto con la capilla de las Trinidades, de la Colegiata de San Isidro, son las obras fundamentales del artista madrileño ${ }^{47}$.

\section{Una obra de mujeres para mujeres: la capilla de la Virgen de Guadalupe}

La palabra capilla nos evoca a una estancia, que puede ser pequeña o grande, pero cuando uno sube la escalera principal de las Descalzas Reales y se dirige al ala Este del claustro superior, buscando la capilla de la Guadalupe, lo que se levanta ante los ojos del espectador, al descubrirse la celosía, es un pequeño camarín, un retablo dedicado a la Virgen literalmente instalado en uno de los muros del claustro. Sin embargo, la sensación que se experimenta es la de estar ante una auténtica maravilla del detalle y el ornato propia del Barroco español, de la majestuosidad del siglo XVII: setenta y tres espejos pintados, ${ }^{48}$ junto con la imagen de la Virgen, un altar de bronce con la Inmaculada Concepción y una bella arquitectura ornamental, que componen el escenario creado en 1653 por una monja real y un artista total (fig. 1) ${ }^{49}$.

El conjunto, de gran riqueza y esplendor, cuidadosamente pensado y ejecutado, destaca antes de abrirse al público por la belleza del enrejado. Realizado en madera dorada, como el resto de las paredes del camarín, está coronado por un frontón ricamente decorado con motivos vegetales arremolinados, muy característicos de Sebastián de Herrera Barnuevo, como demuestran los dibujos preparatorios que de él se conservan ${ }^{50}$. Sin embargo, lo más destacable del exterior de la capilla, son las dos águilas reales de los Habsburgo ${ }^{51}$; imponentes seres alados que suntuosamente guardan la inscripción en la que se especifica la fecha de su realización y el nombre de la promotora, Sor Ana Dorotea, y de su padre, el emperador Rodolfo II: "Surgere quam cernis speciosis cullibus ara mentis honos, animi pignus amoris opus quos heroniniae sacrae pepereret triumphos Mariae adscribit laudibus arte potens filia Rodulfi pietati insignis, et armis, nobilior Christo quam Dorothea dicta. Plena sub hoc uno tot vive nomine gesta ni Maria daret non habitura decus. Anno MDCLIII"52. Tanto las águilas como la inscripción podrían entenderse como una doble declaración de intenciones de Sor Ana Dorotea: por un lado, reclamar su posición ante el claustro como hija de Rodolfo II, ya que, como se ha expuesto previamente, su nacimiento fue fruto de una relación extramarital; y, por otro, exaltar y salvaguardar el poder y el linaje de los Habsburgo, dinastía a la que perte-

47 DíAz GARCÍA, 2010, p. 35.

48 Como explica Abraham Díaz García, Wethey indica que son sesenta y ocho espejos, cuando en realidad hay setenta y tres: veintiún espejos con las heroínas del Viejo Testamento, el central del frontal de altar con la Inmaculada Concepción, cincuenta y dos de menor tamaño que se disponen en altar, gradas y dosel y un gran espejo central tras la escultura de la Virgen con el niño del siglo XVI. DíAz GarcíA, 2010, p. 36.

49 Leticia SÁnchez HernÁndez, "La Capilla de Guadalupe en el Monasterio de las Descalzas Reales", en Gloria Franco Rubio y Ma Ángeles Pérez Samper (eds.), Herederas de Clío. Mujeres que han impulsado la historia, Sevilla, Mergablum, 2014, pp. 493-513.

50 Wethey y SunDERLAND, 1966, p. 17.

51 Apunta Wethey su parecido con otras águilas de Herrera, como la que aparece en el ya citado retrato de Carlos II niño de la colección Gil Nebot. WetheY y SundERLAND, 1966, p. 17.

${ }^{52} \mathrm{La}$ inscripción en latín, traducida al castellano dice: "El altar que contemplas en hermosas ceremonias, honor de la mente, dedicación del alma, trabajo del amor, describe el triunfo de las heroínas sagradas ejecutado en alabanza a María. Dorotea, versada en el arte, hija de Rodolfo, que fue destacado en piedad y distinguido en guerra en el servicio de Cristo, lo dedica. Bajo este nombre de María todos los hechos sobreviven, los cuales no habrían alcanzado la gloria sino por la gracia de María. Año de 1653". SÁNCHez Hernández, 2014, p. 494; DíAZ García, 2010, p. 109; Wethey y Sunderland, 1966, p. 20. 


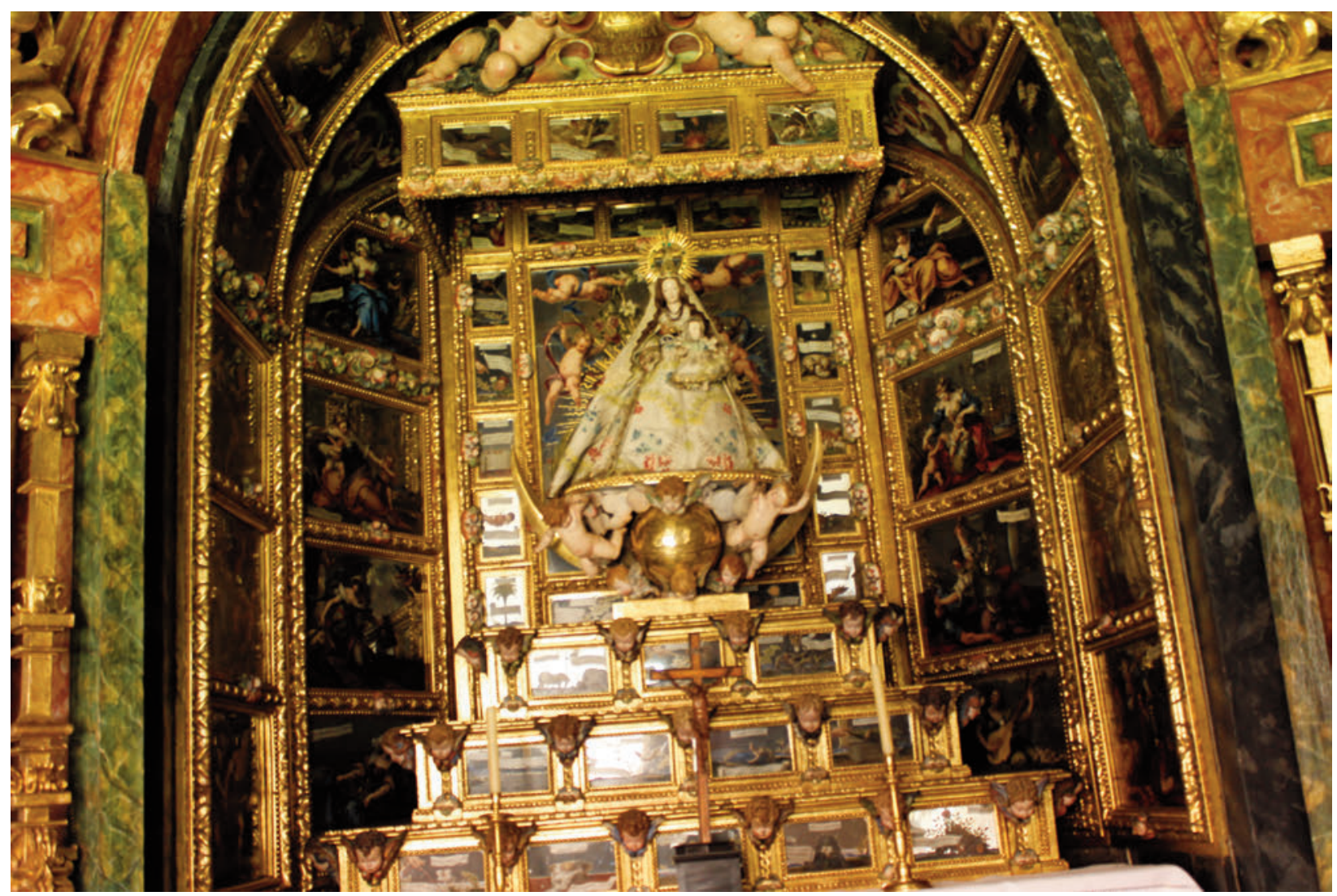

Fig. 1. Sebastián de Herrera Barnuevo, Capilla de la Virgen de Guadalupe, 1653. Madrid, Monasterio de Nuestra Señora de la Consolación, Descalzas Reales.

necía y a la cual trataba de mantener unida y proteger sus intereses con sus intervenciones políticas y, como vemos, también con las artísticas. Por su parte, Herrera, con estas esculturas de la parte superior del enrejado, demuestra su maestría como escultor, saber transmitido por su padre, y su gran capacidad intelectual e inventiva para el diseño decorativo, pues la calidad de las mismas es ejemplar.

Una vez abierta la celosía, se erige ante el espectador un esplendoroso altar-retablo que ocupa el espacio de un arco de medio punto y se divide, mediante unos listones de madera dorada, en una serie de espejos pintado al óleo. ${ }^{53}$ Estos espejos invaden la totalidad de la capilla, desde el frontal de la mesa del altar hasta el intradós del arco, creando un todo articulado por una temática común y una decoración conectiva, pero también por el juego ejercido por la superposición de unas pinturas en otras, ya que el fondo de cada uno de los óleos es el reflejo de una parte del retablo, y por los efectos lumínicos fruto también de la refracción, que otorga un carácter altamente plástico al conjunto arquitectónico. La decoración de la arquitectura la componen motivos vegetales y querubines, muy típicos del estilo de Herrera por su dinamismo y en los que se aprecia la influencia canesca en la rotundidad de sus formas. Los querubines que se encuentran sobre el dosel flanquean y sostienen la inscripción que dedica la capilla a la Virgen de Guadalupe, cuya imagen debía encontrarse en el centro del camarín; sin embargo, la que existe en la actualidad no es obra de Herrera Barnuevo, pues su talla desaparece en fecha desconocida y es remplazada por una imagen de la Virgen con el niño del siglo XVI. Tras la imagen, un gran espejo central decorado con querubines que por-

53 DíAz GARCÍA, 2010, p. 35. 


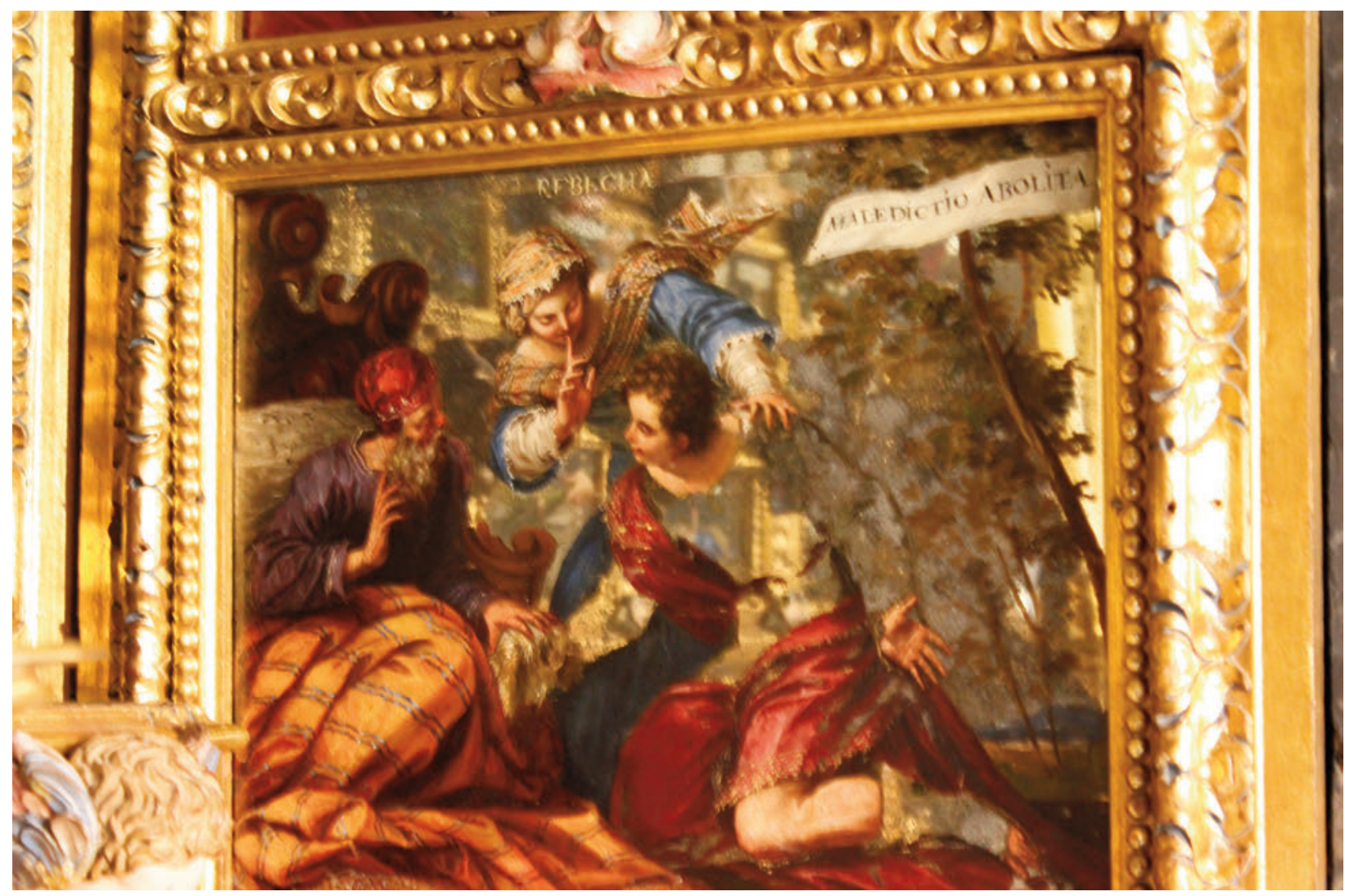

Fig. 2. Sebastián de Herrera Barnuevo, Rebeca, 1653, óleo sobre espejo. Madrid, Monasterio de Nuestra Señora de la Consolación, Descalzas Reales.

tan coronas de flores en dirección a la talla de la Virgen. Rodeando a la Virgen con el niño se encuentran una serie de paneles alegóricos que representan un ciclo de la vida de María: cincuenta y dos escenas con motivos alegóricos que evocan diferentes escenas del Antiguo y Nuevo Testamento en referencia a la vida de la Virgen, los cuales por sus motivos simbólicos no serían fáciles de reconocer pero que cuentan con el acompañamiento de un fragmento del texto bíblico ${ }^{54}$.

Por su parte, el frontal de altar, hecho en bronce, cuenta con una de las figuras más bellas de la composición: la Inmaculada Concepción. También representada al óleo sobre un espejo, como el resto de las pinturas que componen el retablo, aparece sobre la luna creciente elevándose sobre la serpiente, como símbolo de su triunfo sobre el pecado original. Las manos extendidas, con vestido rosa y manto azul, está rodeada de querubines y de su propio paño, que la envuelve en una especie de espiral, que junto con una pincelada rápida de reflejos blancos, crea una sensación de aura celestial al estilo de los pintores venecianos que sirven de inspiración a Herrera ${ }^{55}$.

Sin embargo, pictóricamente lo más destacado de esta capilla son los espejos con las pinturas de las mujeres fuertes del viejo Testamento, pues representan un grupo de alto valor iconográfico e iconológico. Estas figuras femeninas conforman un conjunto excepcional dentro de la producción pictórica del barroco hispánico, ya que, incluso individualmente, son un tema muy poco recurrente en la iconografía barroca

\footnotetext{
54 Wethey y Sunderland, 1966, pp. 22-25; SÁnCHEZ Hernández, 2014, pp. 507-513.

55 WeTHEY Y SUNDERLAND, 1966, p. 18.
} 


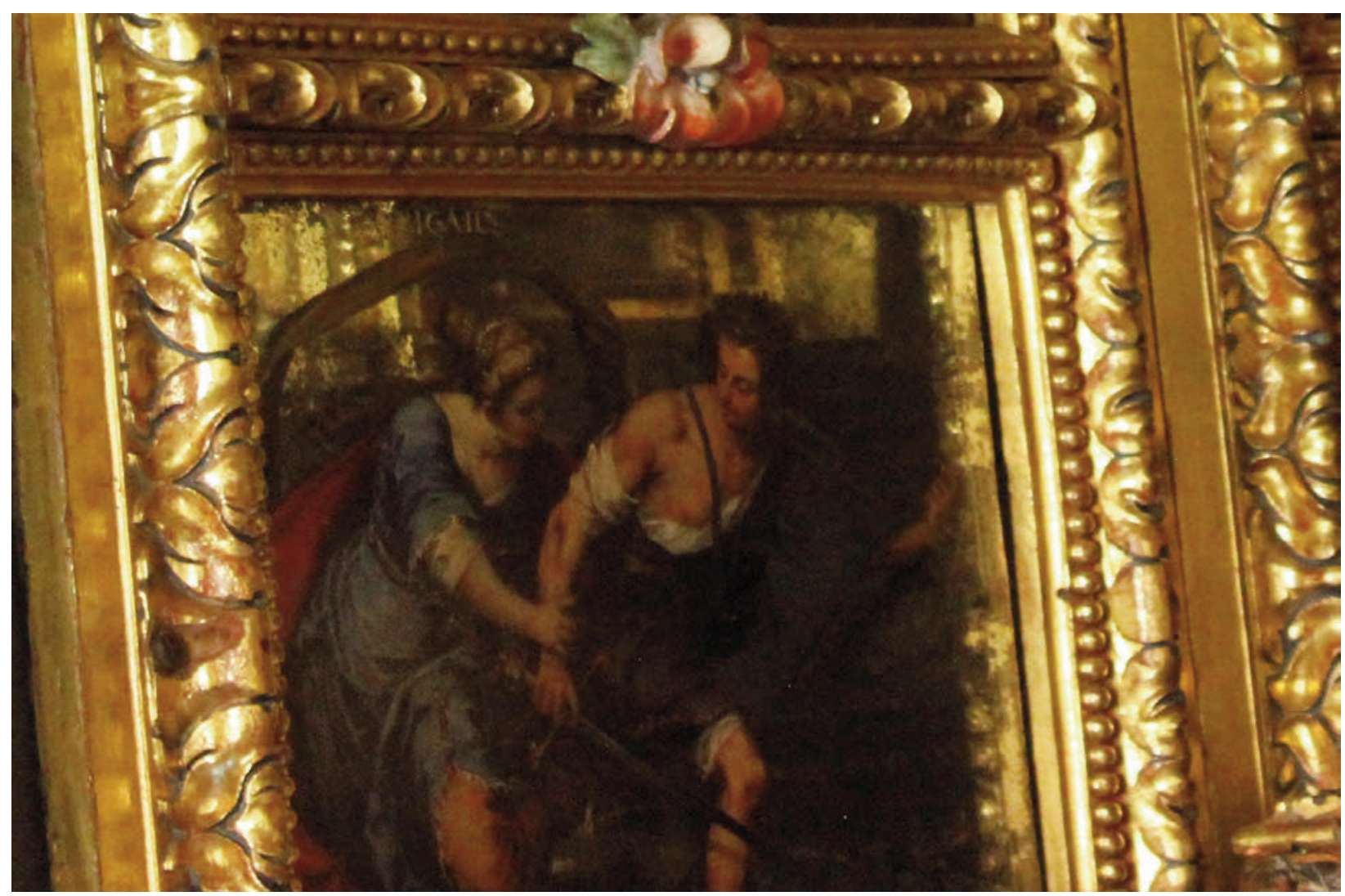

Fig. 3. Sebastián de Herrera Barnuevo, Abigail, 1653, óleo sobre espejo. Madrid, Monasterio de Nuestra Señora de la Consolación, Descalzas Reales.

española del siglo XVII. Para la concepción del programa, sor Ana Dorotea se inspira en el libro de Martín Carrillo Elogio de las mujeres insignes del viejo testamento, escrito en 1627 en honor de su tía, Sor Margarita de la Cruz. El libro cuenta con cuarenta y siete capítulos dedicados a las figuras de cincuenta y cuatro mujeres ejemplares del antiguo testamento, extrayendo los textos de la Vulgata y rematando cada uno de los capítulos con un soneto de un poeta de la época de Martín Carrillo ${ }^{56}$.

Para formar parte de su bello camarín, Sor Ana Dorotea escoge dieciocho de las cincuenta y cuatro mujeres que Martín Carrillo recoge en su obra, y Herrera Barnuevo las dispondrá a ambos lados del altarretablo y por el intradós del arco de medio punto. Prácticamente la totalidad de los espejos pintados al óleo por Herrera llevan escritos con letras doradas el nombre de las heroínas bíblicas, lo que agiliza su identificación por parte del espectador. Wethey y Sunderland, en el primer estudio realizado de la capilla, observaron que los espejos de los tres primeros niveles se disponían por parejas, de modo que al espejo exterior de un lado del altar-retablo le correspondería el exterior del contrario, y los dos internos formarían, a su vez, pareja ${ }^{57}$. De este modo a la figura de Rebeca (fig. 2), en el extremo inferior derecho, con su mano en el labio en señal de silencio en el momento en el que Isaac ofrece su bendición a Jacob, le corresponde como pareja la figura de Abigail (fig. 3), en el extremo inferior izquierdo, la cual sujeta la el brazo de David, que se marcha con la espada en la mano. Junto a Rebeca, se encuentra María, hermana de Moisés

\footnotetext{
56 SÁNCHEZ HeRnÁNDEZ, 2016, p. 141.

57 Wethey y Sunderland, 1966, p. 20; Díaz García, 2010, p. 36.
} 


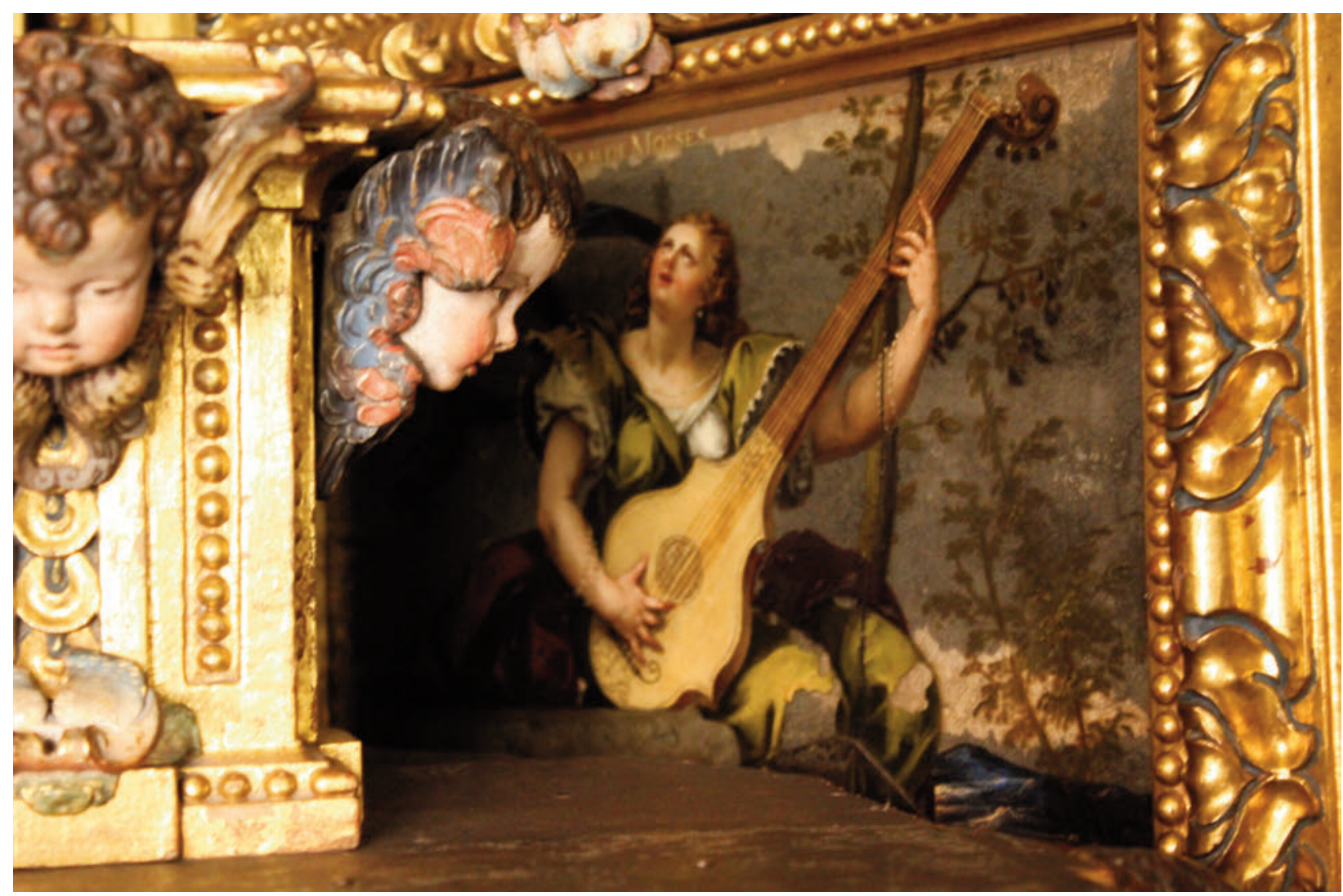

Fig. 4. Sebastián de Herrera Barnuevo, María, la hermana de Moisés, 1653, óleo sobre espejo. Madrid, Monasterio de Nuestra Señora de la Consolación, Descalzas Reales.

(fig. 4), tocando un laúd con los ojos entornados hacia arriba a la izquierda, y hace pareja con Abisag (fig. 5), a la derecha de Abigail, que se representa como una hermosa joven que porta flores sobre su regazo con su cabeza volteada a la derecha. En la segunda fila, la reina Esther junto a Asuero (fig. 6), hace pareja con la reina Saba (fig. 7), que se representa con el rey Salomón. A la izquierda de Esther, la valiente Jael (fig. 8) se encuentra atestando el golpe mortal en la sien del general Sísara, haciendo pareja en el lado contrario con la valerosa Judith (fig. 9), que porta en una mano la cabeza del general Holofernes y en la otra la espada con la que acomete su gran acción, mientras el cuerpo decapitado del enemigo de Betulia yace a su izquierda. En la tercera hilera, Débora (fig. 10) como jueza de su pueblo se encuentra en posición sedente, como su pareja, la madre de Sansón (fig. 11), que porta el disco del sol mirando cada una hacia el lado en el que se encuentra su compañera. Junto a Débora, Raquel (fig. 12) con sus dos hijos, mostrando el poder de la gracia divina que permite la maternidad a una mujer estéril, que hace pareja con Sara (fig. 13), mujer de Abraham que concibe un hijo del mismo modo, por intervención divina.

Como bien explica Abraham Díaz García, la disposición de las parejas se complica en este punto. En la cuarta fila, tan solo Noemí (fig. 14) y Axa (fig. 15), una observando lo que hay sobre el suelo y la otra mirando como emana el agua de un surtidor de la tierra, hacen pareja del mismo modo que en las tres filas interiores. La Sunamita, que se encuentra en el extremo derecho, se interrelaciona con el panel superior exterior, que es el de Ana, la madre de Samuel (fig. 16), ya que ambas portan a su hijo, la primera entregándoselo a Eliseo y la segunda presentándolo en el templo; y lo mismo ocurre con la viuda Sarepta (fig. 17) y la figura que se encuentra sobre ella, Ruth (fig. 18), una aparece ofreciendo un mendrugo de pan al profeta Elías y la segunda entregando unas espigas a su suegra Noemí. Los tres últimos paneles, que serían los de Betsabé coronando a Salomón (fig. 19), Día o Mañana y Acohol, hijas de Job, son los más difíciles de rela- 


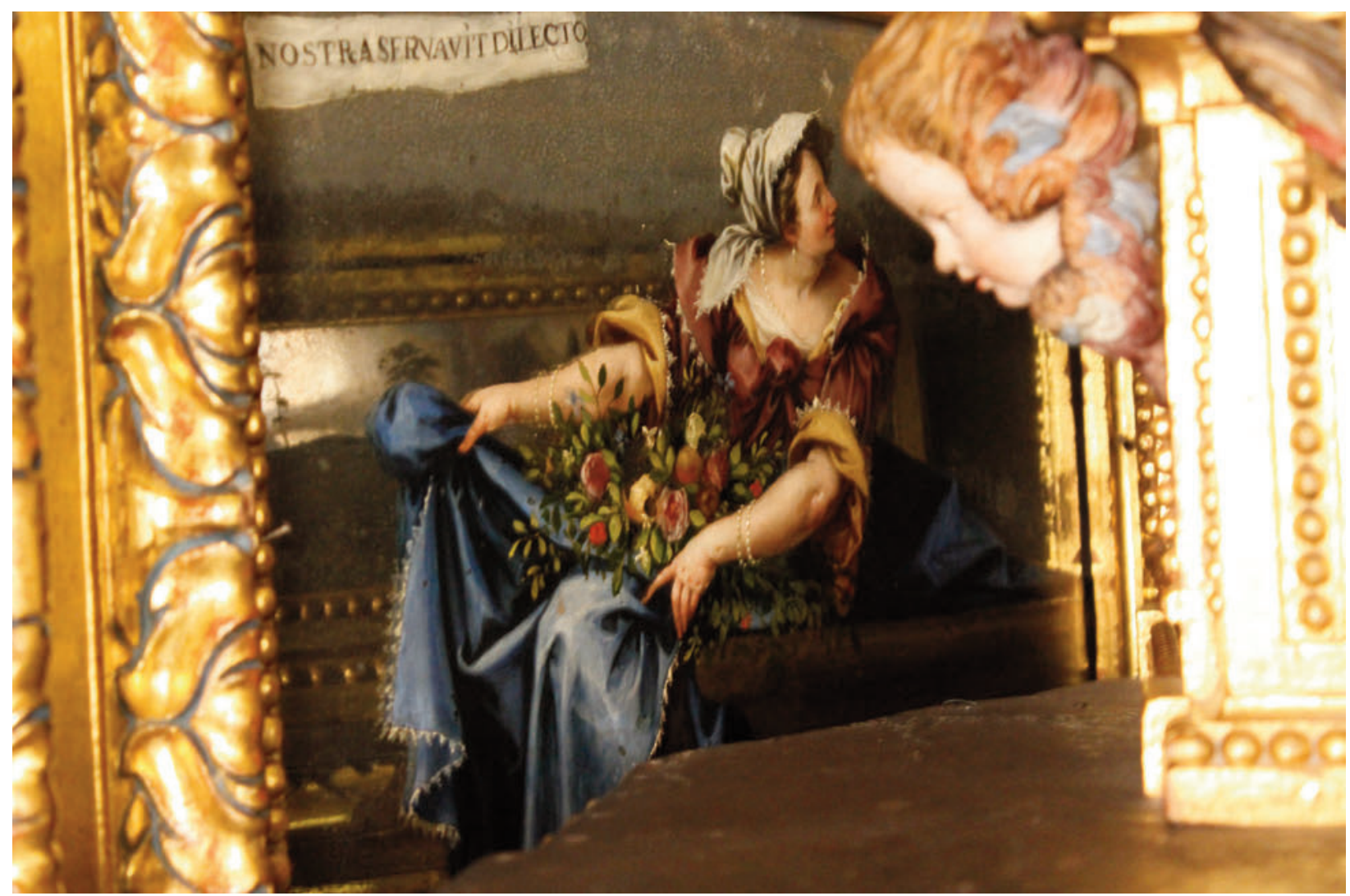

Fig. 5. Sebastián de Herrera Barnuevo, Abisag, 1653, óleo sobre espejo. Madrid, Monasterio de Nuestra Señora de la Consolación, Descalzas Reales.

cionar $^{58}$ (fig. 20). Según Wethey y Sunderland, Betsabé iría emparejada con Alcohol, quedando suelto el espejo de Día o Mañana ${ }^{59}$, teoría apoyada por Díaz García, aunque no se ofrece una explicación sobre la relación iconográfica u iconológica que existe entre Betsabé y Alcohol, o sobre el motivo de la soledad del espejo de Día ${ }^{60}$.

Todas juntas forman un conjunto insólito pues, a pesar de que las mujeres fuertes del viejo testamento habían sido empleadas en muchas ocasiones como prefiguración de la Virgen, y si bien es cierto que aquí también cumplen esa función simbólica, cabría pensar que debido a la utilización del libro de Carrillo como fuente primaria para su creación, a su emplazamiento en un centro de poder femenino particular como las Descalzas Real y a la propia vida y trayectoria personal de Sor Ana Dorotea, estamos ante un retablo con una carga simbólica mayor que la podemos apreciar a primera vista.

58 Las únicas figuras presentes en la capilla de Sor Ana Dorotea y Herrera Barnuevo que no están presentes en el libro de Martín Carrillo, es decir, que no utilizan los Elogios de las mujeres insignes del viejo testamento como fuente literaria para la creación de su iconografía, son las dos hijas de Job, Alcohol y Día, cuya fuente es el Libro de Job. WeTHEY y SundERLAND, 1966, pp. 29-30.

59 El nombre original en hebreo de Día o Mañana, la hija de Job, es Jemima, que significa "originada del día", como explica Fray Luis de León en su obra sobre el Libro de Job, también se le otorga en su traducción al castellano el nombre de Paloma (que atrae la luz), y precisamente Día porta en su mano, mientras parece emerger del cielo, el Sol, por lo que podría tratarse de una personificación del Espíritu Santo o de Dios Padre, lo que haría que pudiese formar pareja con el espejo de la Inmaculada Concepción que preside el frontal de altar y que se encuentra justamente debajo del espejo en el que se representa Día. Estamos trabajando para realizar un análisis iconográfico exhaustivo de las obras, para verificar esta hipótesis, así como la relación que pueda haber entre Betsabé y Alcohol. Para más información sobre las hijas de Job y otras hipótesis: Alba y SEIJAS, 2015, pp. 121.

60 Wethey y Sunderland, 1966, p. 21; Díaz García, 2010, p. 38. 


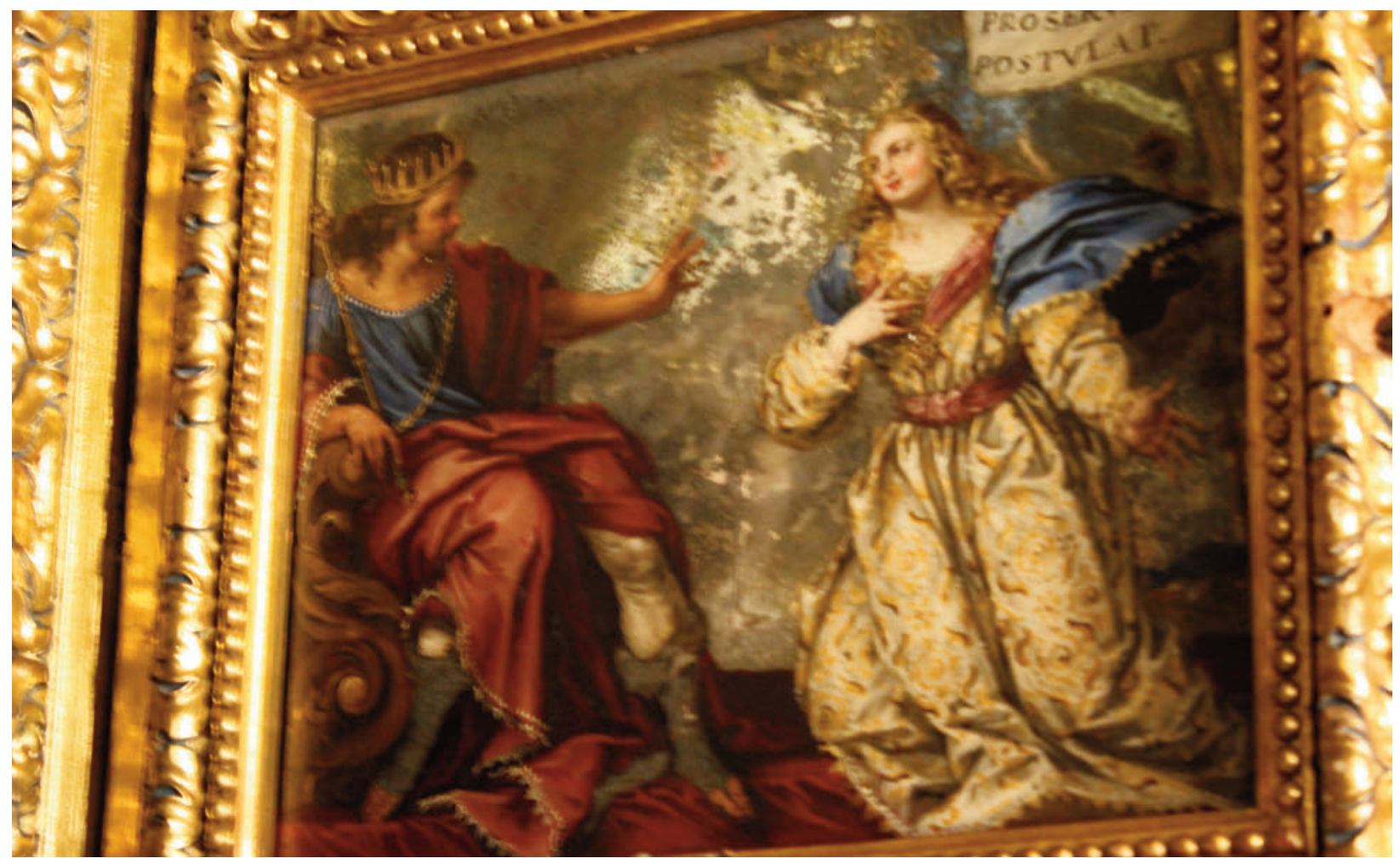

Fig. 6. Sebastián de Herrera Barnuevo, La reina Esther, 1653, óleo sobre espejo. Madrid, Monasterio de Nuestra Señora de la Consolación, Descalzas Reales.

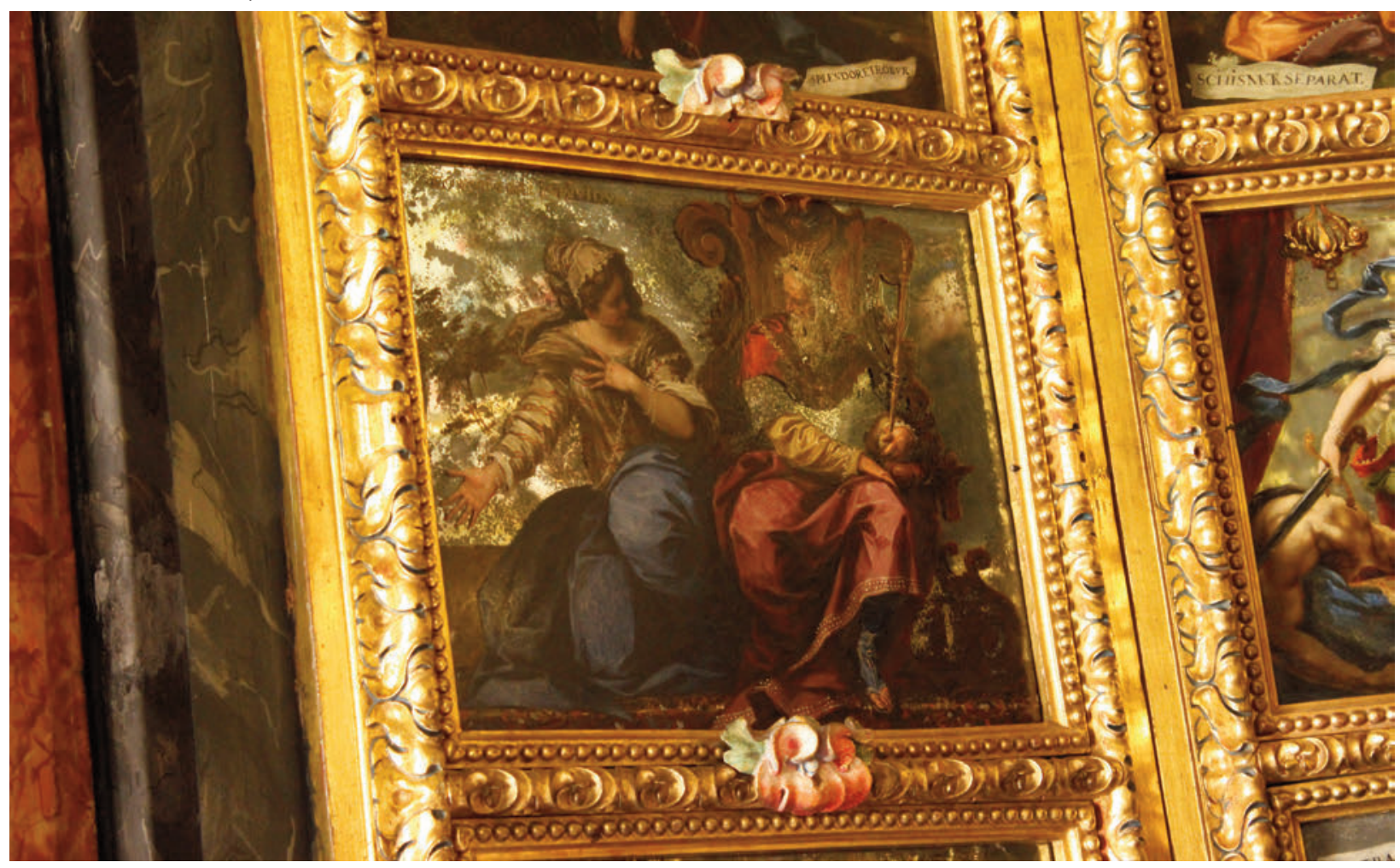

Fig. 7. Sebastián de Herrera Barnuevo, La reina de Saba, 1653, óleo sobre espejo. Madrid, Monasterio de Nuestra Señora de la Consolación, Descalzas Reales. 


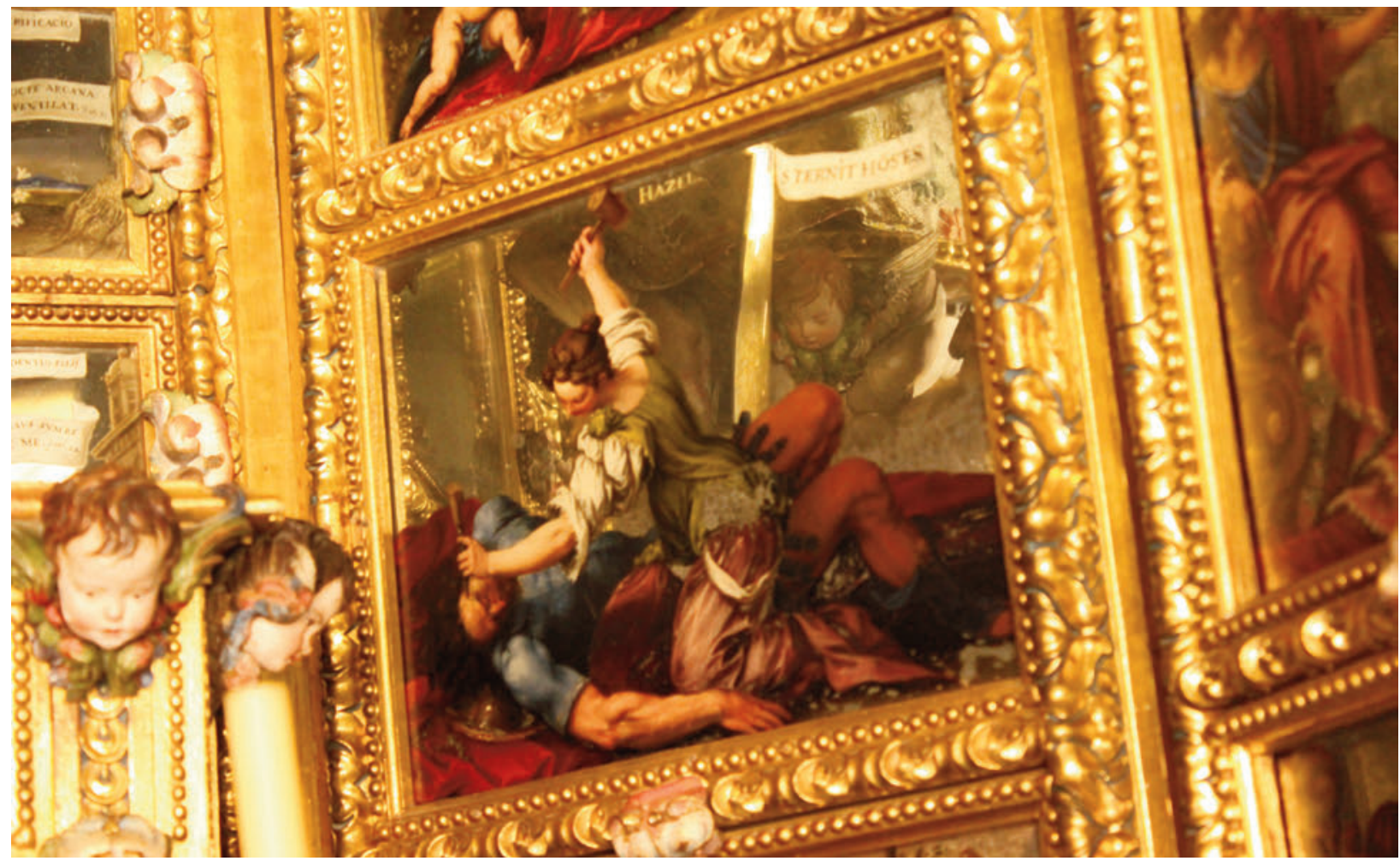

Fig. 8. Sebastián de Herrera Barnuevo, Jael, 1653, óleo sobre espejo. Madrid, Monasterio de Nuestra Señora de la Consolación, Descalzas Reales.

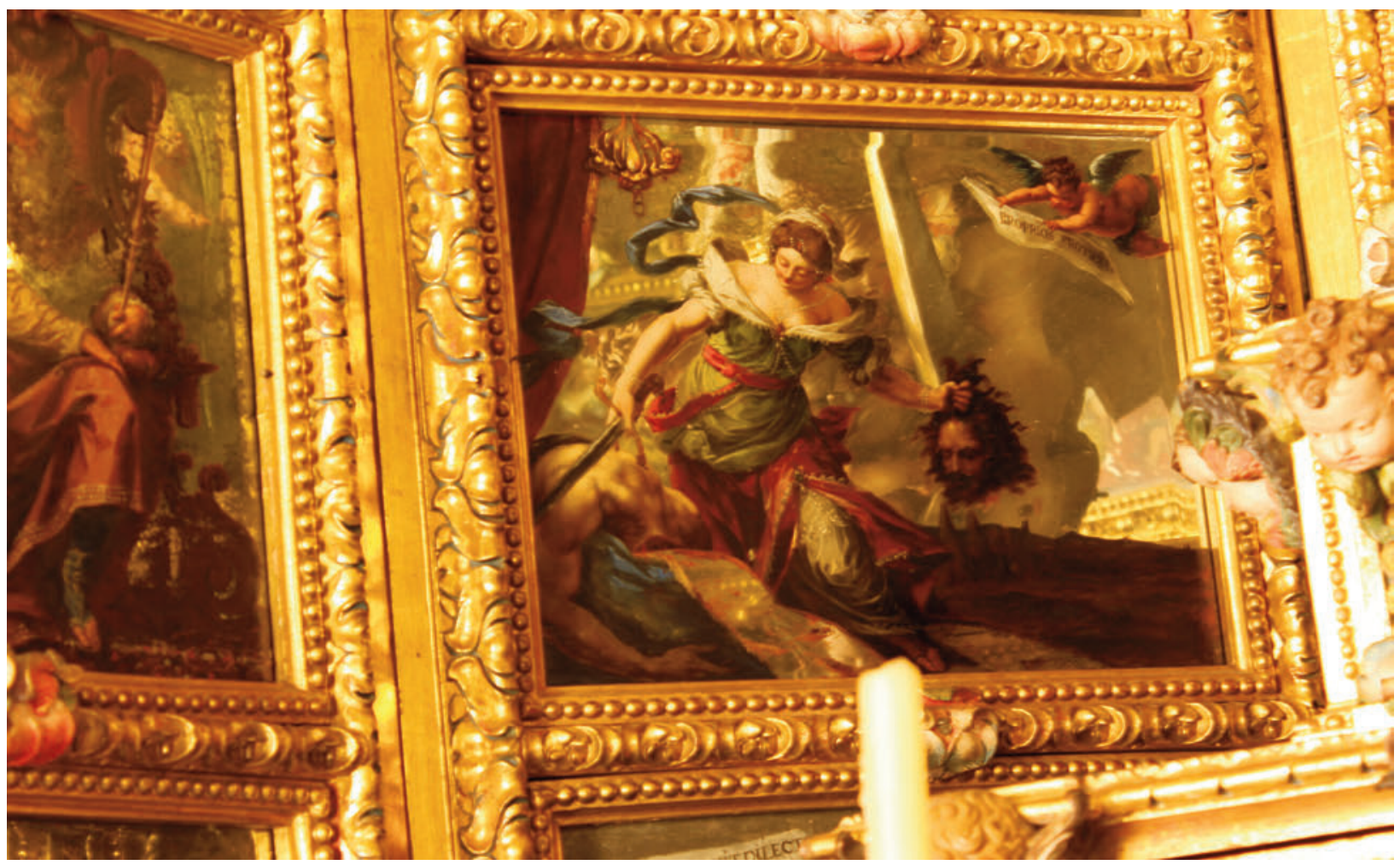

Fig. 9. Sebastián de Herrera Barnuevo, Judith, 1653, óleo sobre espejo. Madrid, Monasterio de Nuestra Señora de la Consolación, Descalzas Reales. Madrid, Monasterio de Nuestra Señora de la Consolación, Descalzas Reales. 


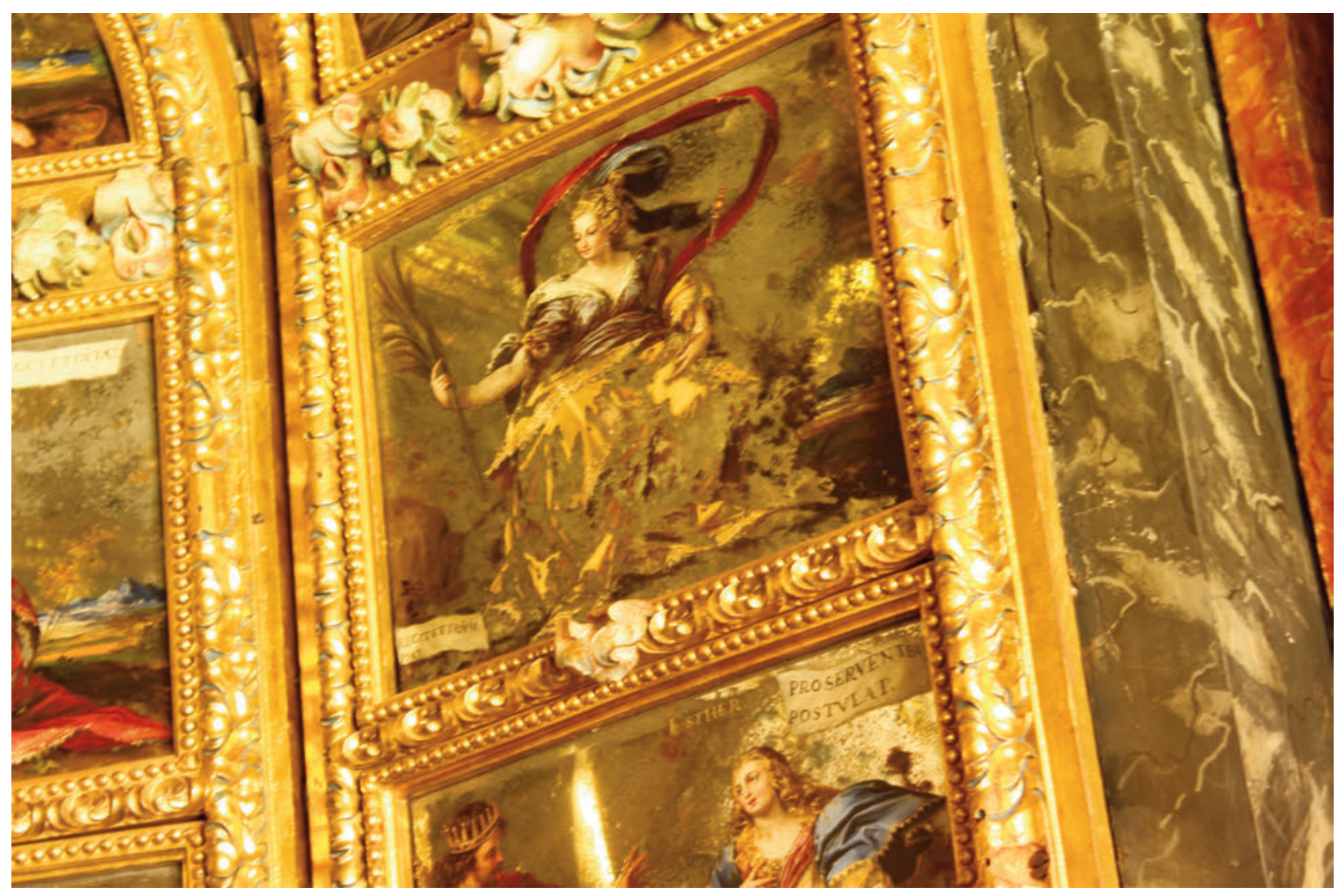

Fig. 10. Sebastián de Herrera Barnuevo, Débora, 1653, óleo sobre espejo. Madrid, Monasterio de Nuestra Señora de la Consolación, Descalzas Reales.

María Leticia Sánchez Hernández explica que este libro y esta capilla deben verse como un claro ejemplo de cómo las católicas se aproximaban a la lectura de la Biblia "a través de un libro espiritual, y cómo el texto se transforma en imagen para ser contemplado de manera pedagógica" ${ }^{2}$. Sin embargo, a pesar de que es cierto que la mujer en esta época, tras el Concilio de Trento, tenía dificultades para el acceso a una lectura directa de la Biblia y que su acercamiento a la misma se realizaba a través de interpretaciones masculinas del texto sagrado, ya fuesen de sus confesores, de los moralistas, de los libros de devoción o de los catecismos, en el caso del libro de Martín Carrillo y de la capilla de la Virgen de Guadalupe no parece que sea esa la única motivación que lleva a la redacción del libro o a la realización de la capilla.

La obra de Carrillo fue escrita, como decíamos, en 1627 para sor Margarita de la Cruz, quien en esa fecha contaba con sesenta años de edad, por encargo de ella misma. Es decir, no es un libro realizado por deseo de su autor sino que se trata del cumplimiento de una promesa a una monja real de la que su hermano había sido confesor, y como bien expone el propio Carrillo en la dedicatoria de la edición de 1627, el motivo de su redacción fue para dar a conocer al mundo la ejemplaridad y excepcionalidad de Margarita de la Cruz para que pudiese competir en valor, virtud y santidad con las mismísimas heroínas de la Biblia ${ }^{62}$.

61 SÁnchez Hernández, 2016, p. 141; Rosilie Hérnandez, "The Politics of Exemplarity: Biblical Women and the Education of the Spanish Lady in Martín Carrillo, Sebastian de Herrera Barnuevo and Maria de Guevara”, en A. J. Cruz y R. Hernández (eds.), Women's Literacy in Early Modern Spain and the New World, England, Ashgate, 2011, pp. 225-241 (p. 226).

${ }^{62}$ Magdalena S. SÁnchez, The Empress, the Queen and the Nun. Women and Power in the Court of Philip III, Baltimore, John Hopkins University Press, 2002. 


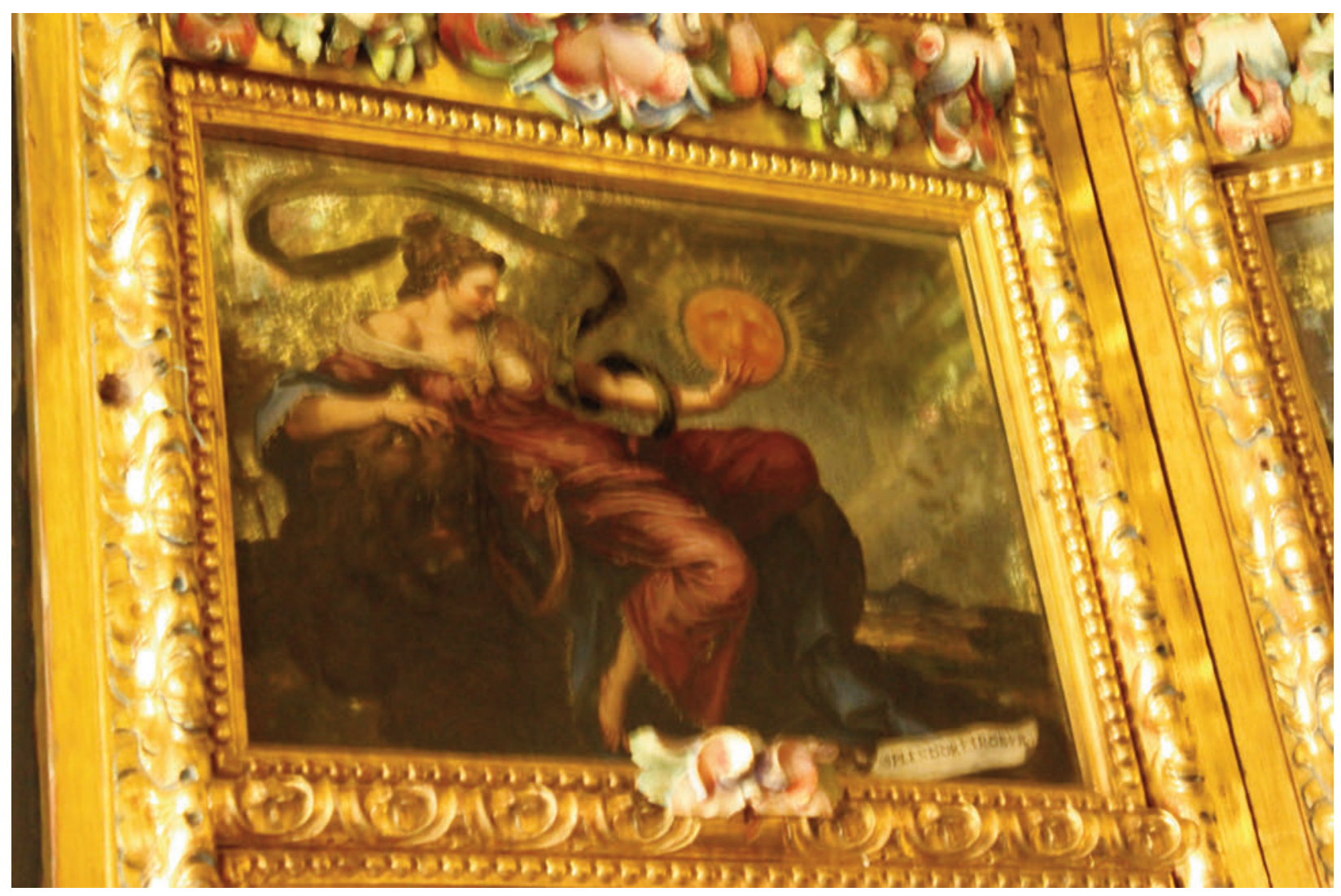

Fig. 11. Sebastián de Herrera Barnuevo, La madre de Sansón, 1653, óleo sobre espejo. Madrid, Monasterio de Nuestra Señora de la Consolación, Descalzas Reales.

De este modo, con su publicación, se vería que "[...] en todos los tiempos Dios ha concedido a la tierra mujeres santas a quien respetar, nobles a quien honrar, valerosas a quien loar, y virtuosas a quien imitar", siendo Sor Margarita de la Cruz una más de ellas. Por lo tanto, además de un ejemplo de herramienta para la educación, el libro parece un homenaje a una mujer que trata de equipararse a sí misma a las mujeres más insignes del viejo testamento. Además, como explica Rosilie Hernández, el libro de Carrillo tenía una audiencia muy concreta: las franciscanas descalzas que habitaban en el convento, pertenecientes a la familia real o a los linajes más prestigiosos del territorio español y cuya vocación religiosa y vida espiritual estaba intrínsecamente conectada con los círculos de poder de la corte. ${ }^{63}$ Por eso, parece que estas mujeres del viejo testamento se presentan para equipararse tanto a Sor Margarita como a las monjas de las Descalzas, reivindicando, de este modo, su papel, poder y cualidades, dentro de la escena político-social del momento, en mundo dominado en exclusiva en favor de los intereses del género masculino. Por lo tanto, con el nacimiento del libro podríamos estar ante una puesta en valor de unas determinadas actitudes y aptitudes femeninas que les eran negadas por considerarse propias tan solo del género masculino (valor, inteligencia, astucia, sacrificio, prudencia...), pero que están presentes en las mujeres fuertes del antiguo testamento. De este modo, Sor Margarita de la Cruz estaría utilizando la literatura como herramienta de propaganda, construyendo una justificación de su personalidad y posición a través de las figuras de las heroínas bíblicas, por lo que más que modelos a imitar ${ }^{64}$, las mujeres fuertes,

\footnotetext{
63 HeRnÁNDEZ, 2011, p. 228.

64 HernándeZ, 2011, p. 230.
} 


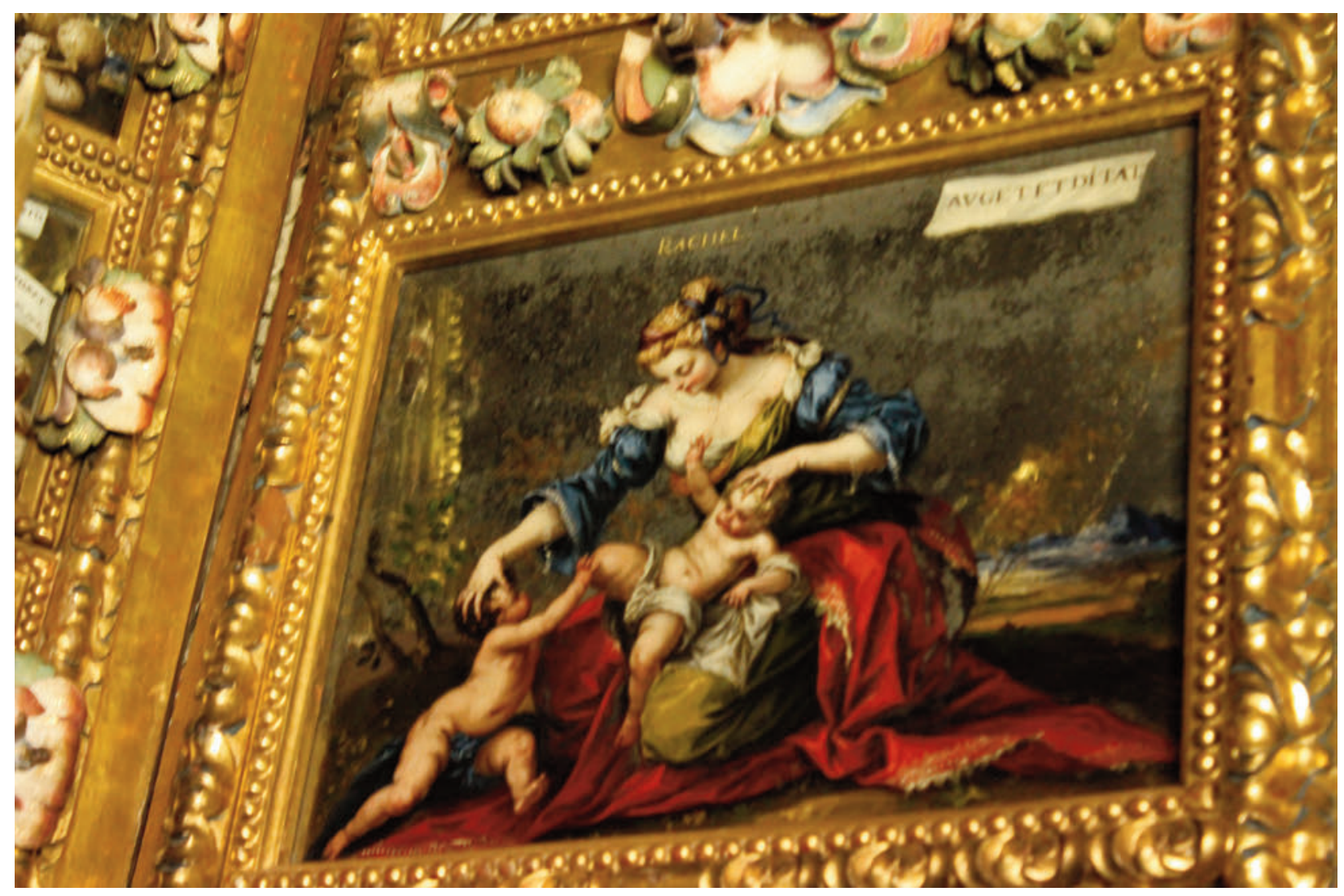

Fig. 12. Sebastián de Herrera Barnuevo, Raquel, 1653, óleo sobre espejo. Madrid, Monasterio de Nuestra Señora de la Consolación, Descalzas Reales.

además de una prefiguración de la Virgen María, podrían entenderse como una prefiguración de ella misma.

Del mismo modo, la capilla de la Virgen de Guadalupe podría entenderse que cumple una función similar, aunque más compleja. Se ha partido de la tesis de Wethey y Sunderland de que la capilla es un ciclo mariano, cuya creación responde a un deseo de manifestar el apoyo de la dinastía Habsburgo al dogma inmaculista $^{65}$, tan importante tras el Concilio de Trento, que nace de la presencia de las águilas de la Casa de Austria coronando el conjunto. Sin embargo, si bien es cierto que su función de apoyo al dogma de la Inmaculada no puede ser puesta en duda, analizando la vida de Sor Ana Dorotea y el papel que en ella juega la figura de su tía, la presencia de las águilas sujetando la inscripción con su nombre y el de su padre, Rodolfo II, junto con el bello óleo de la Inmaculada Concepción, también podrían tener una significación más personal. Por un lado, la inscripción, con su nombre y el de su padre sustentado por el emblema de la Casa de Austria, podría haber sido concebido como una legitimización de su propio linaje y ascendencia; por otro, debido al hecho de que Sor Margarita de la Cruz, que no había sido madre, reclamase su presencia en el convento, la criase y educase como a una hija sin haberla concebido, también otorga justificación de índole sentimental y personal a la presencia de la Inmaculada Concepción en la iconografía del altar-retablo.

Y lo mismo ocurre con las heroínas bíblicas. Sor Ana Dorotea, conoce el libro que Carrillo había escrito por petición de su tía y lo emplea como fuente literaria para que Herrera Barnuevo realice las pinturas

65 Wethey y Sunderland, 1966, pp. 19-20. 


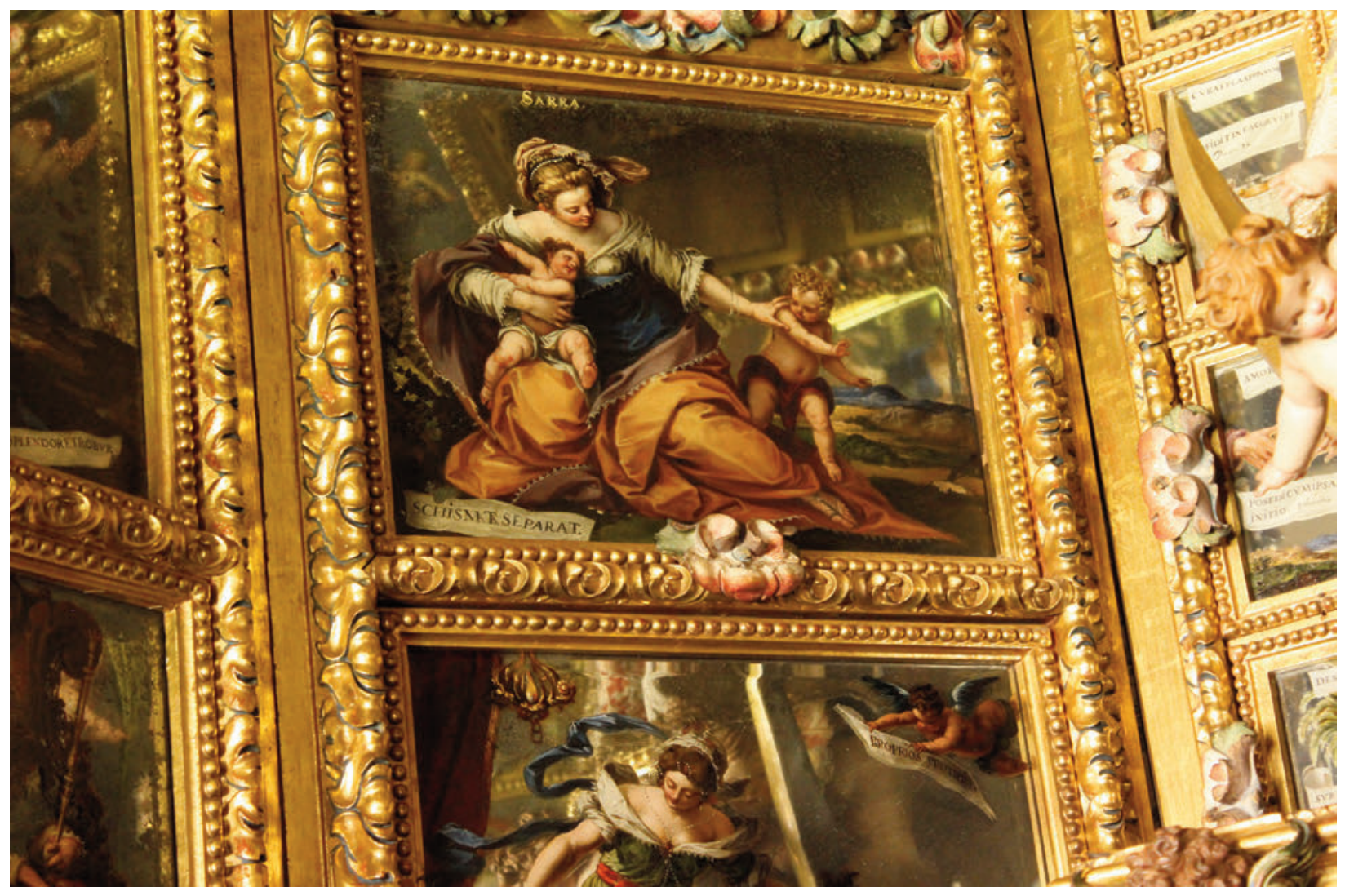

Fig. 13. Sebastián de Herrera Barnuevo, Sara, 1653, óleo sobre espejo. Madrid, Monasterio de Nuestra Señora de la Consolación, Descalzas Reales.

de las mujeres fuertes; de nuevo, Sor Ana Dorotea, sigue los pasos de la hermana de su padre y quiere reivindicar su papel y poder dentro del mundo político y social de la época y también el de todas las mujeres de la dinastía Habsburgo que la precedieron en las Descalzas, pero manifestando al mismo tiempo su pureza, religiosidad y espiritualidad. Seguramente por este motivo, del libro de Carrillo escoge dieciocho de las cincuenta y cuatro mujeres fuertes que aparecen en los elogios ${ }^{66}$, las cuales pertenecen a dos grupos bien diferenciados. Por un lado, selecciona a las mujeres gobernantes, valientes e inteligentes, que supieron gobernar sus pueblos o ayudarlos en momentos desesperados con acciones arriesgadas, como Esther, Saba, Judith o Jael. Por otro lado, presenta a las madres abnegadas que aun siendo estériles Dios las hizo madres por su bondad y profunda espiritualidad, como la madre de Samuel, Sara, Miriam la hermana de Moisés o Ruth. Como expone Rosilie Hernández, las referencias cruzadas de estas obras figuras femeninas son claras y tendrían como fin confirmar, autorizar y extender la idea, dentro la comunidad religiosa y a todo aquel que pudiese visitar el monasterio ${ }^{67}$, de que las habitantes que allí residían no solo eran fieles sirvientas a Dios sino también actrices poderosas de la escena política del imperio hispánico ${ }^{68}$. Además, también inculcaba la idea de la maternidad sin concepción pues ellas mismas, al educarse y criarse unas a otras dentro de la comunidad de la formaban parte, actuaban como abnegadas madres espirituales, como había hecho

66 Axa, Alcohol y Día son las tres excepciones que aparecen en los elogios del libro de Carrillo.

${ }^{67}$ Se trata de un monasterio de clausura por lo que las obras de arte que en él se encuentran estaban fuera del ojo público pero, como se ha expresado anteriormente, en él residieron durante algún tiempo diversos miembros de la dinastía Habsburgo.

68 HeRnÁNDEZ, 2011, p. 237. 


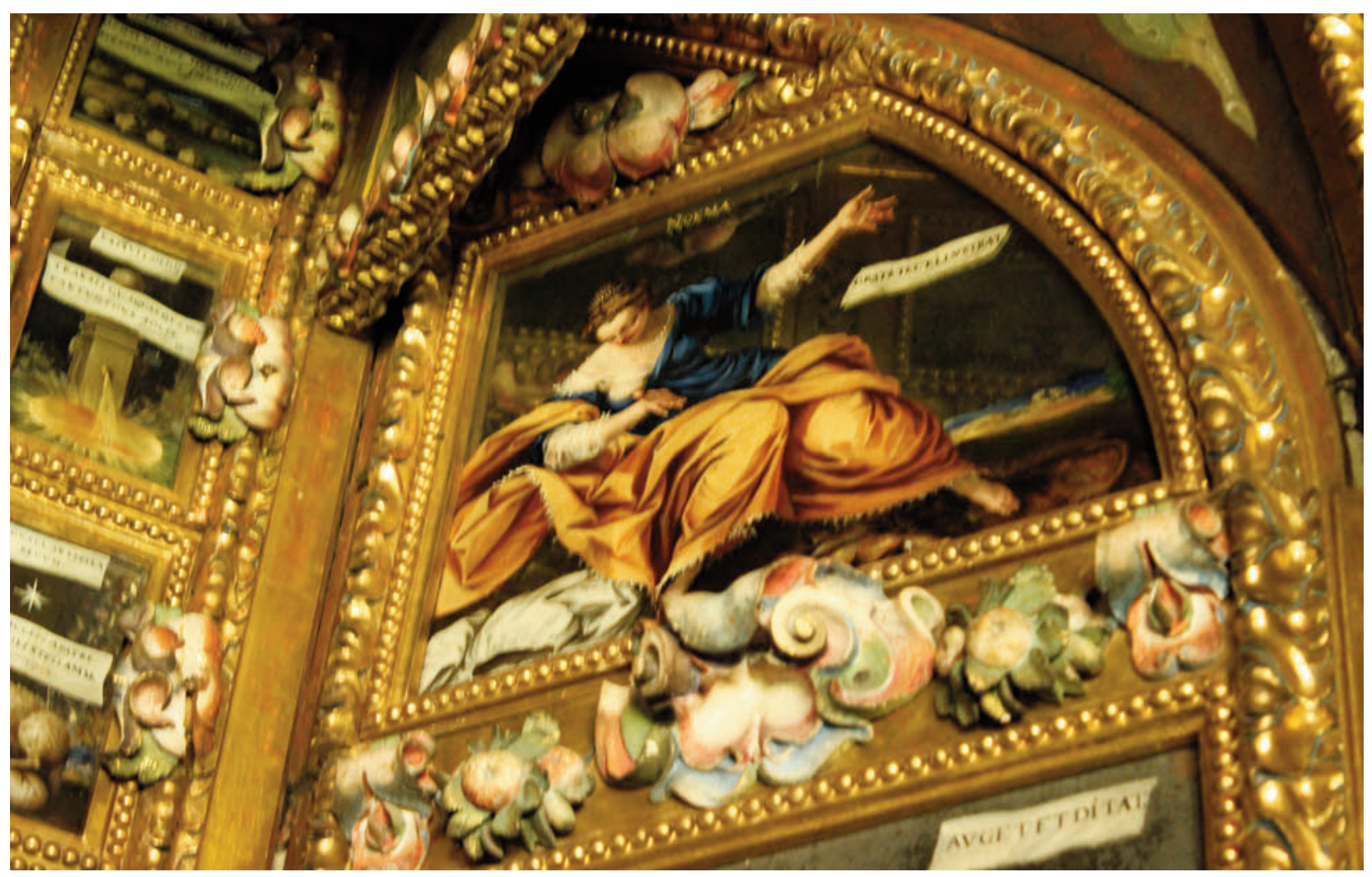

Fig. 14. Sebastián de Herrera Barnuevo, Noemí, 1653, óleo sobre espejo. Madrid, Monasterio de Nuestra Señora de la Consolación, Descalzas Reales.

Sor Margarita de la Cruz con su sobrina de niña, y la Virgen con el hijo de Dios. Por lo tanto, Ana Dorotea y sus compañeras al observar el altar-retablo además de ver un ciclo mariano que veneraban tendrían un espejo al que mirarse, pues se verían a ellas mismas reflejadas en esas pinturas como ejemplos de coraje, valentía, astucia, inteligencia, fuerza, prudencia y piedad; $y$, al mismo tiempo, estarían ante un símbolo de sus abnegadas "madres" 69 , aquellas que las habían precedido y luchado por ese bastión de poder femenino en el que habitaban y a quienes verdaderamente debían emular: Sor Juana de Austria, la Emperatriz María, la reina Margarita de Austria o Sor Margarita de la Cruz.

Asimismo, esta idea se refuerza por la propia materialidad de las pinturas que conforman la capilla. Como se ha expuesto anteriormente, todas están realizadas sobre espejo, lo que consigue que, al carecer de fondo, unas pinturas se reflejen en otras, es decir, que las mujeres se fusionen entre sí. Esto hace que a pesar de encontrarnos con dos grupos diferenciados de mujeres fuertes, las valerosas gobernantes y las madres abnegadas, todas ellas se entrelacen, se interconecten unas con las otras, reflejando a su vez, la propia personalidad de las monjas que habitaban en el monasterio, partidarias de la indisolubilidad del binomio fepolítica. Así el espejo es, en sí mismo, un símbolo, y lo es desde dos puntos de vista: por un lado, permite la fusión de la iconografía en un todo, reflejando unas mujeres en las otras, haciendo de las heroínas bíblicas una sola, lo cual también podría haber sido pensado como prefiguración conjunta de la propia Virgen; y, por otro lado, las monjas debían verse reflejadas en la capilla, y el espejo, con su poder reflectante, ayudaría a que ellas se identificasen con todas esas figuras, símbolos de la construcción de un género femenino transgresor que trataban de erigir, al verse ellas mismas reflejadas al contemplar la capilla.

69 Hernández, 2011, p. 237. 


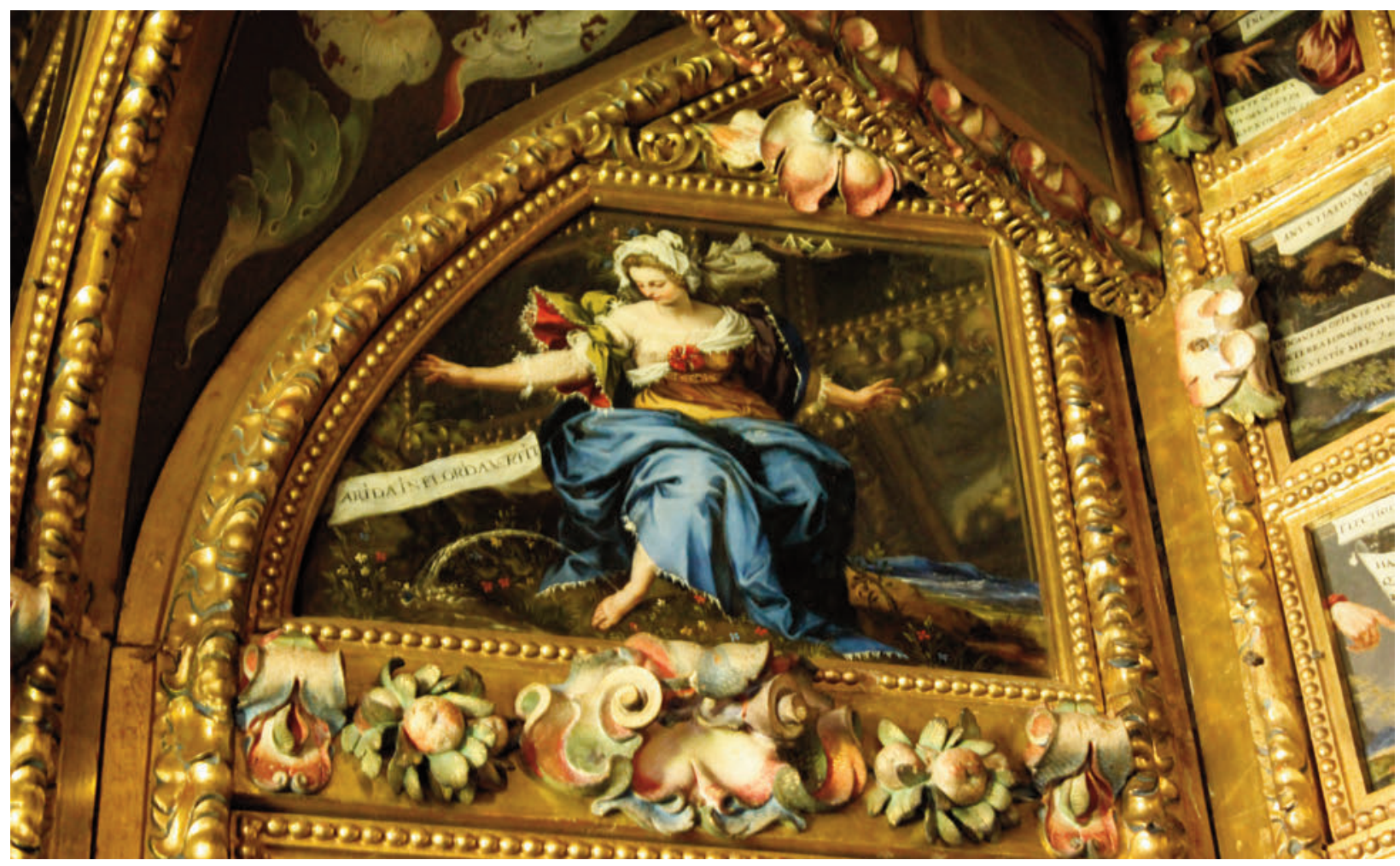

Fig. 15. Sebastián de Herrera Barnuevo, Axa, 1653, óleo sobre espejo. Madrid, Monasterio de Nuestra Señora de la Consolación, Descalzas Reales.

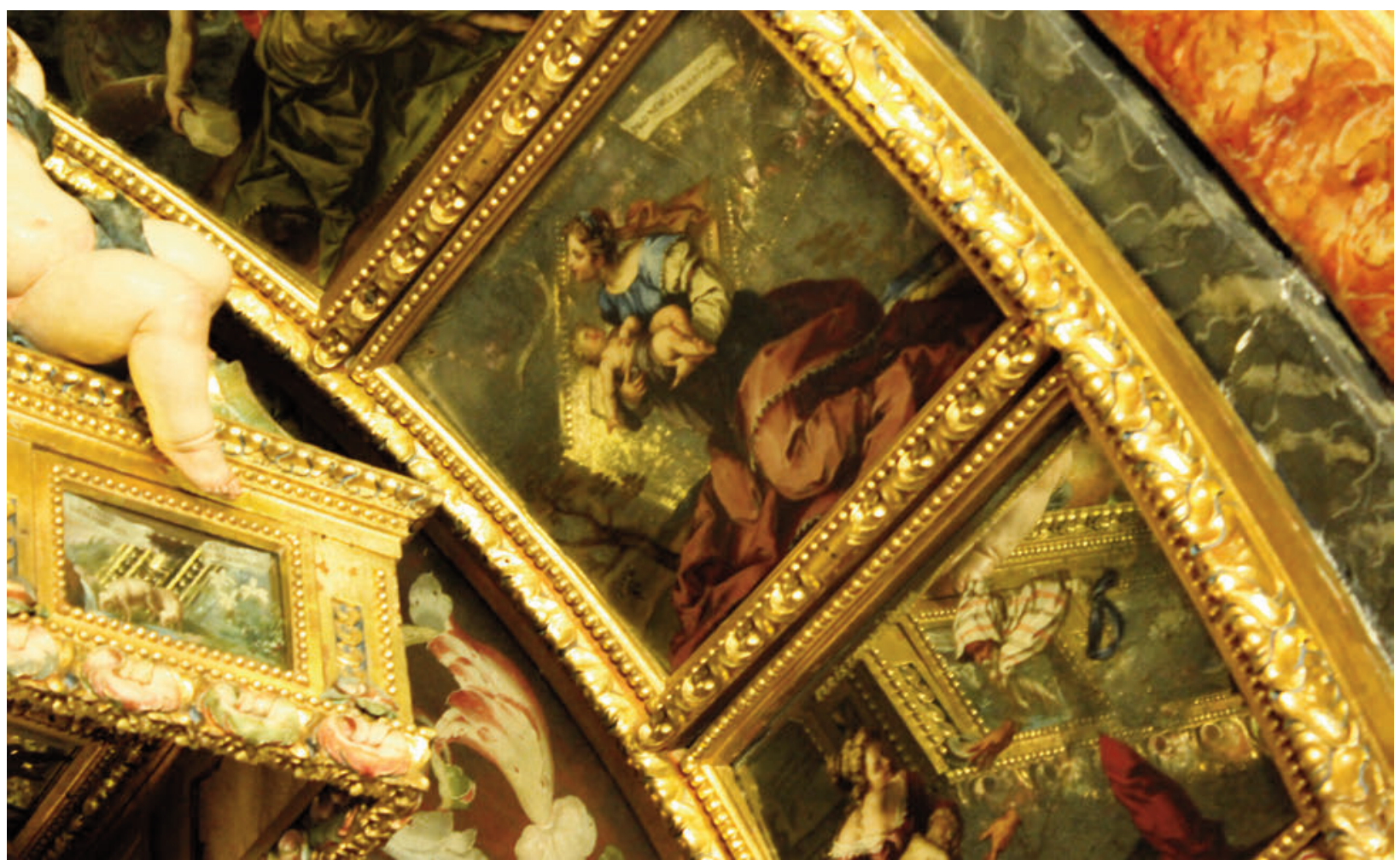

Fig. 16. Sebastián de Herrera Barnuevo, La sunamita, 1653, óleo sobre espejo. Madrid, Monasterio de Nuestra Señora de la Consolación, Descalzas Reales. 


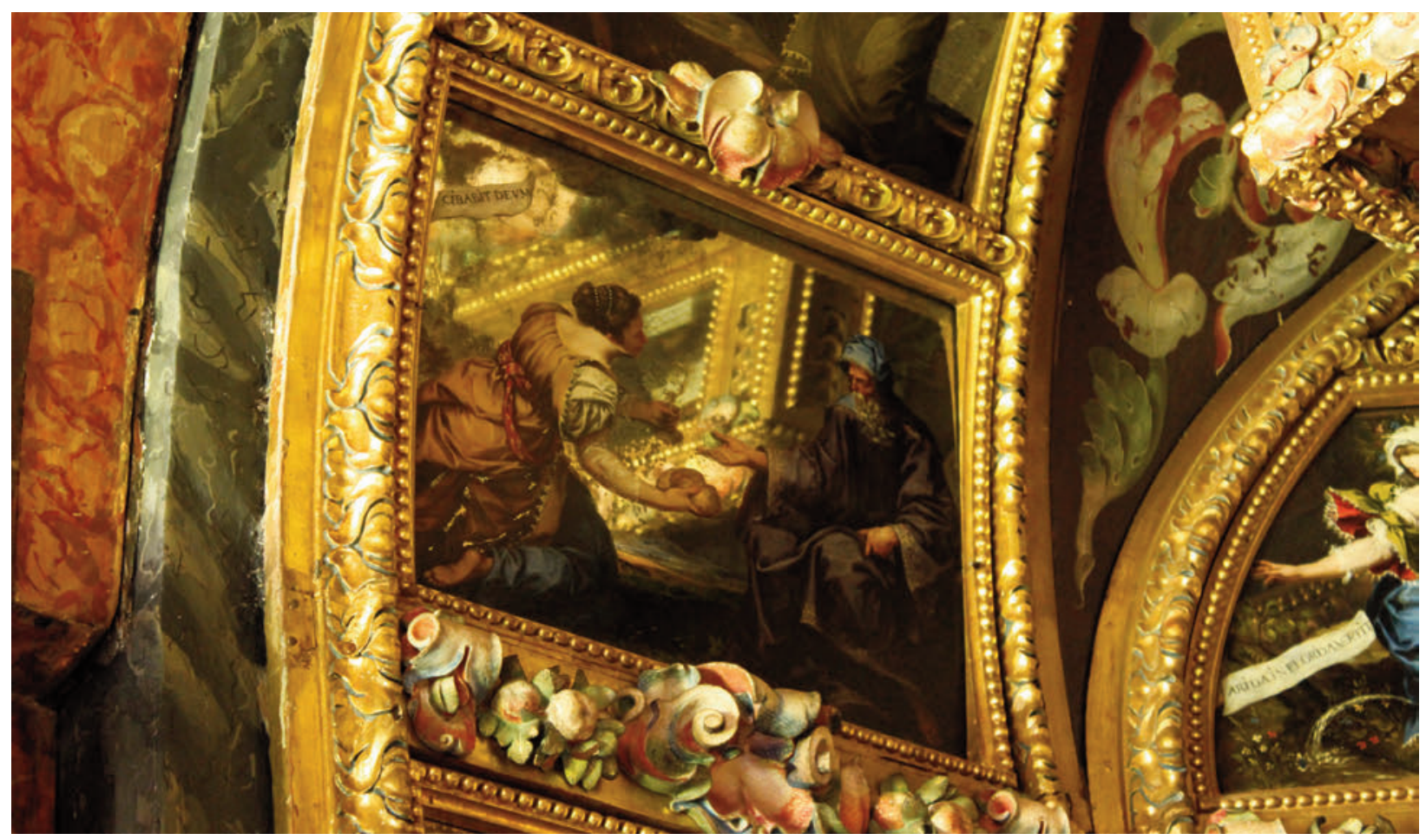

Fig. 17. Sebastián de Herrera Barnuevo, Ana la madre de Samuel, 1653, óleo sobre espejo. Madrid, Monasterio de Nuestra Señora de la Consolación, Descalzas Reales. Sebastián de Herrera Barnuevo, La viuda Sarepta, 1653, óleo sobre espejo. Madrid, Monasterio de Nuestra Señora de la Consolación, Descalzas Reales.

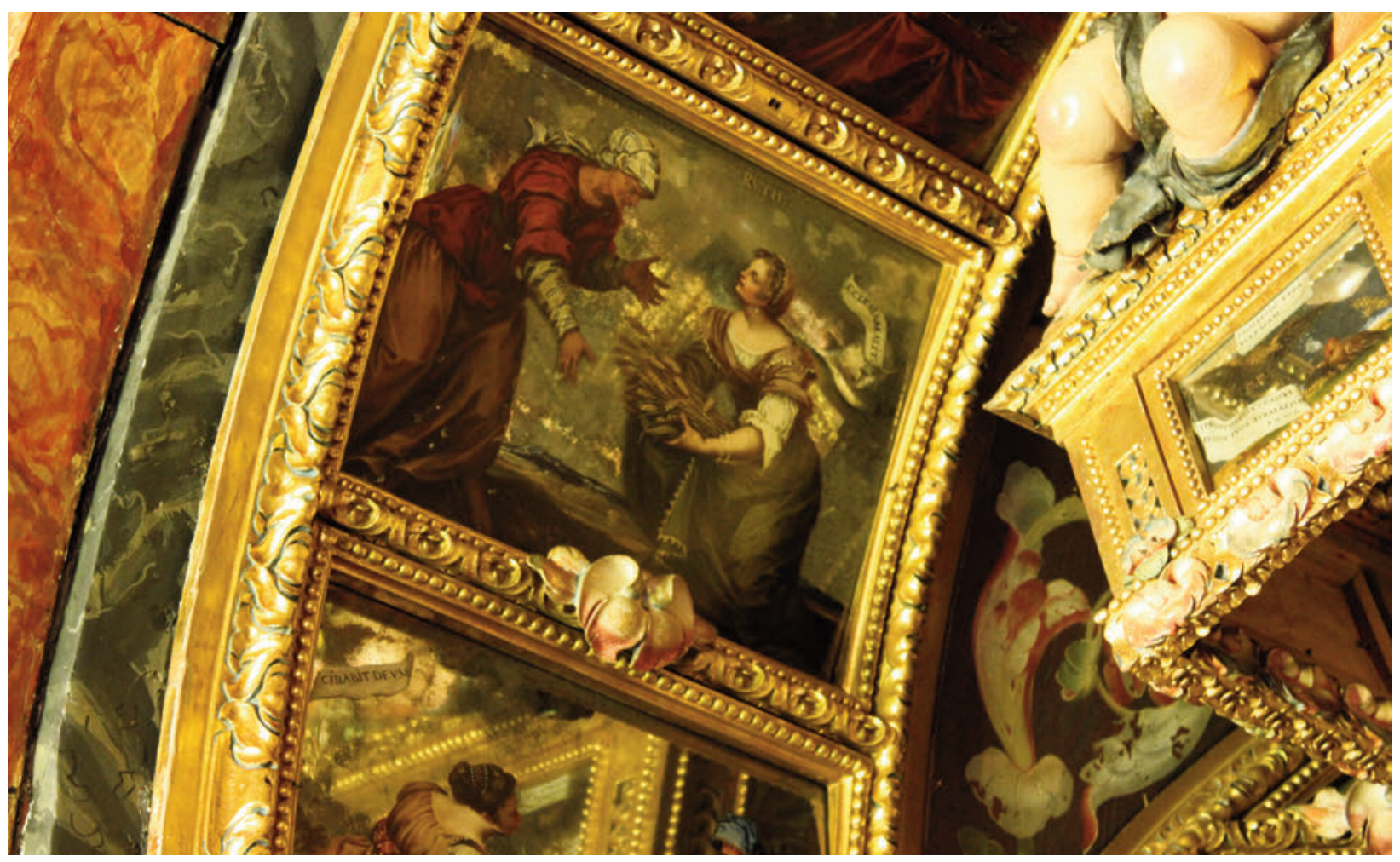

Fig. 18. Sebastián de Herrera Barnuevo, Ruth, 1653, óleo sobre espejo. Madrid, Monasterio de Nuestra Señora de la Consolación, Descalzas Reales. 
Por lo tanto, estamos ante una oda a la mujer desde diversas perspectivas. Por una parte, a la mujer como madre, educadora, protectora, piadosa y pura, simbolizada en esas mujeres que obtuvieron el fruto de sus entrañas por gracia divina; por otra, a la mujer inteligente, valiente y sacrificada, capaz de enfrentarse a peligros por salvar a su pueblo, como Judith y Jael, o que es capaz de gobernarlo con astucia y juicio, como la reina Esther y la reina de Saba. Todas ellas encarnan y prefiguran las virtudes de la Virgen, protagonista de la capilla, pero al mismo tiempo representan todo aquello que caracteriza a las habitantes de la fundación de Juana de Austria. Desde los gruesos muros del monasterio, desde las robustas paredes del claustro, muchas de las mujeres que habitaron las Descalzas llevaron una doble vida, basada en la espiritualidad profunda pero combinada con un fuerte sentido del deber político y social, que las llevó a establecer contactos más allá de la clausura para lograr interceder por sus intereses en la Corte, los de su familia e incluso los de la propia Iglesia.

De este modo Sor Ana Dorotea creó junto con la hábil mano de Sebastián de Herrera Barnuevo un espacio representativo de sí misma y de aquellas que la rodeaban. Ideó con espejos un espejo en el que mirarse y que hiciese recordar a las franciscanas descalzas de dónde venían, quiénes las habían precedido y cómo la historia bíblica había sabido ofrecer modelos de mujeres fuertes capaces de seguir las enseñanzas de Dios, cuidar y proteger a la suyos, y a la vez ser parte activa de la Historia de sus pueblo. Herrera, por su parte, supo ejecutar un espacio donde se combina magistralmente la adoración y veneración a la Virgen María, el apoyo de los Habsburgo al dogma inmaculista y el recuerdo de todas aquellas mujeres fuertes que habitaron las Descalzas, quienes junto con la Virgen debían actuar como modelo de las monjas franciscanas que contemplarían la obra. El artista madrileño, en esta capilla crea un espacio donde las tres artes mayores se fusionan en un todo armonioso, entrelazando a la perfección sus saberes, y obteniendo una obra que habla a la vez de Cano, en esos redondos y robustos querubines, y de Tintoretto, en el tratamiento de los paños y en el color veneciano que invade los óleos de las heroínas bíblicas; demostrando en las Descalzas una alta calidad como artista, que permite pensar como habrían sido esas obras que, por desgracia, se han perdido con el paso del tiempo.

Por otra parte, debe tenerse en cuenta que estamos ante un ciclo que es recurrente en la historia del arte, pero que no lo es tanto en el periodo de elaboración de la capilla. Durante el barroco español, tras el Concilio de Trento, determinados temas desaparecen de la iconografía habitual, por considerarse controvertidos o posibles causantes de controversia. El motivo de que la Biblia no fuese una lectura de fácil acceso para la mujer en la época, incluso para la de elevada formación, se debe precisamente al carácter contendiente que se entendía que determinados pasajes podían $\operatorname{poseer}^{70}$, por lo que su lectura llegaba a la mujer a base de interpretaciones redactadas por hombres. Esto hacía que la información que tenía el género femenino, sobre todo del antiguo testamento, fuese muy sesgada. Además, en una momento en la que la mujer debía estar sometida a la protección, amparo y sumisión a una figura masculina, y cuya instrucción estaba dictada por las normas impuestas por el género masculino para su adoctrinamiento, determinadas figuras femeninas de la Biblia podrían ser causantes del surgimiento de pequeñas resistencias, que impidiesen el control poblacional que el Estado patriarcal buscaba. De este modo, las mujeres insignes del viejo testamento se encuentran virtualmente ausentes del panorama pictórico español del Barroco, porque la ambigüedad de algunas no era del agrado de la cultura dirigida impuesta por el pensamiento de la Contrarreforma.

\footnotetext{
70 Como apunta Sánchez Hernández, el Concilio de Trento impuso una férrea normativa que impidió el acceso directo a la lectura de determinados libros, como se aprecia en la publicación del índice de libros prohibidos en 1559; el pueblo se vio excluido de una lectura directa la Biblia, pero no así los varones intelectuales y piadosos, como especifica el propio índice. Por este motivo, a diferencia de las seguidoras de la Reforma, las religiosas católicas tuvieron que valerse de otras vías para un conocimiento de las Sagradas Escrituras, como el texto de Carrillo y su transformación en programa iconográfico. SÁNCHEZ HERNÁNDEZ, 2014, pp. 498-499.
} 


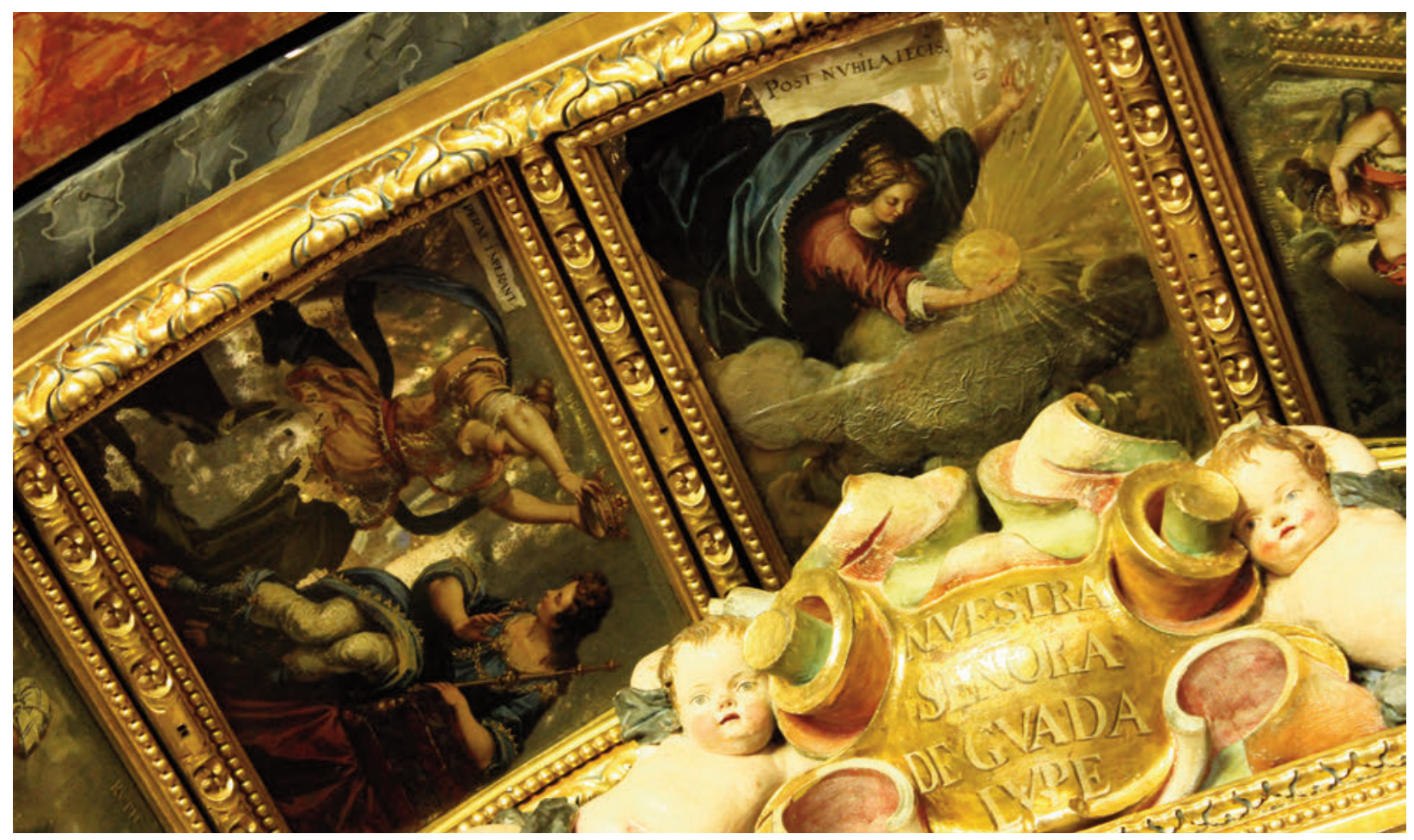

Fig. 19. Sebastián de Herrera Barnuevo, Betsabé, 1653, óleo sobre espejo. Madrid, Monasterio de Nuestra Señora de la Consolación, Descalzas Reales.

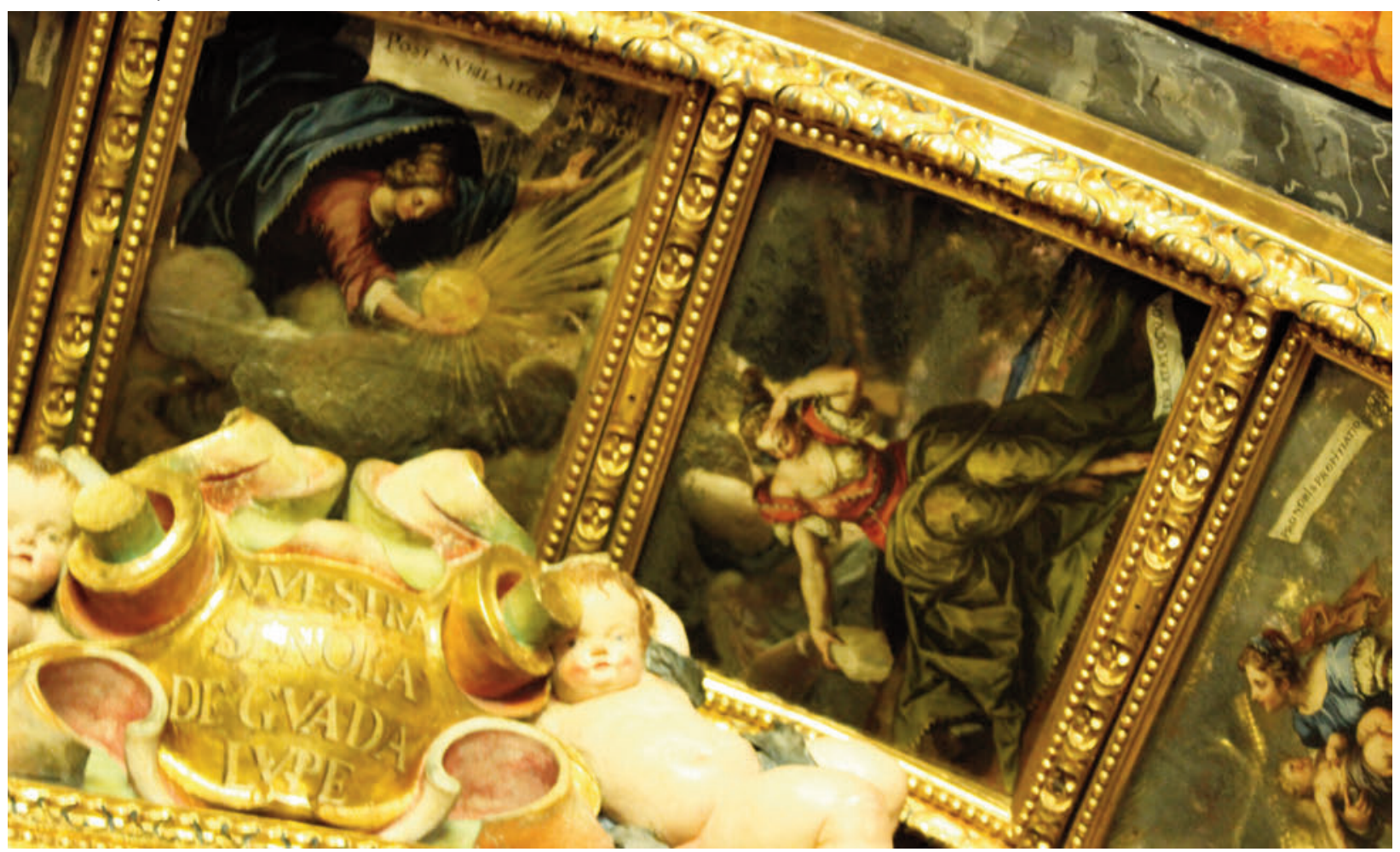

Fig. 20. Sebastián de Herrera Barnuevo, Día o Mañana, 1653, óleo sobre espejo. Madrid, Monasterio de Nuestra Señora de la Consolación, Descalzas Reales. Sebastián de Herrera Barnuevo, Alcohol, 1653, óleo sobre espejo. Madrid, Monasterio de Nuestra Señora de la Consolación, Descalzas Reales. 


\section{Conclusiones}

La capilla de la Virgen de Guadalupe es una obra de arte total, hija del lugar en el que se encuentra, el monasterio de Nuestra Señora de la Consolación, conocido como las Descalzas Reales. Se trata de una joya del barroco madrileño, poco conocida por tres motivos principales: su localización en un convento de clausura de difícil acceso; por la propia disposición de capilla, ya que es un pequeño altar-retablo, suerte de camarín, que se encuentra insertado en los muros del claustro alto y protegido por un tupido enrejado de madera dorada; y por el desconocimiento de su autor, el artista Sebastián Herrera Barnuevo, que aunque Maestro de Obras Reales y pintor de Cámara, la suerte hizo que se perdiese gran parte de su obra y que, con ella, él se perdiese entre otros artistas de su generación.

Sin embargo, con este trabajo se pretendía destacar el valor artístico y simbólico que tiene tanto el monasterio como la capilla, pues una dentro del otro, representan un enclave de poder femenino sin paragón dentro de la monarquía hispánica. Las figuras reales que pasaron por las Descalzas Reales a lo largo de su historia lo convirtieron en uno de los centros femeninos más relevantes de Europa, en el que las monjas que lo habitaron tuvieron consciencia del poder, capacidades y oportunidades que ello les reportaba. Todo esto queda recogido en la figura de Sor Ana Dorotea y en la obra que realizó por su mandato el artista Sebastián de Herrera Barnuevo. La fuerza simbólica de este monumento reside en la fuerza del monasterio mismo, pues se construye como un homenaje a la Virgen a simple vista, pero recorriendo la historia del convento, la vida de las mujeres que lo habitaron y la historia que encierra la propia creación del conjunto de Herrera, donde no existen los cabos sueltos y cada parte funciona como engranaje de una maquinaria armoniosa y bella, que es el conjunto, uno llega a comprender que la historia de la capilla de Virgen de la Guadalupe es como un gran relicario de virtudes y de recuerdos de todas las monjas que allí residieron. Es un lugar para la exaltación de un modelo de virtud que es la Virgen, pero también de todas aquellas mujeres que la antecedieron y encarnaron algunas de sus excelencias, y que tuvieron un importante papel en la Biblia, como heroínas o protagonistas de sus pasajes siempre fieles a los mandatos divinos, es decir, precisamente las virtudes que pretende encarnar su promotora, Sor Ana Dorotea, y el resto de las clarisas descalzas.

En una época en la que los modelos femeninos que ofrece la pintura están dominados por la Virgen y las advocaciones marianas, por la Magdalena arrepentida, y por las santas y mártires sacrificadas, en esta capilla se otorga presencia y relevancia a unas mujeres que personifican todo lo que significa pertenecer a una comunidad como la de Nuestra Señora de la Consolación: el ser una mujer religiosa y espiritual no debe estar reñido con el valor y la inteligencia necesarios para ser mujeres poderosas.

BEGOÑA ÁLVAREZ SEIJO es investigadora contratada FPU por la Universidad de Santiago de Compostela en el Departamento de Historia del Arte, dentro del Grupo de Investigación IACOBUS. Sus investigaciones se centran en la representación de la mujer en la pintura barroca española del siglo XVII; en concreto su tesis doctoral se centra en investigar los motivos de la escasa presencia de las mujeres fuertes del Antiguo Testamento en la pintura de artistas españoles entre 1563-1700. Ha realizado diversas publicaciones centradas en cuestiones de género relativas a la Edad Moderna como "Las mujeres fuertes del antiguo testamento. Un modelo de feminidad para las mujeres de la Corte española en el siglo XVII", en Javier Sierra Sánchez y Jorge Gallardo-Camacho (eds.) Identidades culturales, narrativas creativas y sociedad digital (2018), así como artículos como "La negación de la ambigüedad: Transgénero en la España barroca" Ambigua: revista de investigaciones sobre género y estudios culturales, 4 (2017).

Email: b.alvarez.seijo@usc.es 
